INEEL/EXT-99-00571

May 1999

\title{
CALCULATION OF HYDROGEN AND OXYGEN UPTAKE IN FUEL ROD CLADDING DURING SEVERE ACCIDENTS USING THE INTEGRAL DIFFUSION METHOD
}

\section{FINAL DESIGN REPORT}

L. J. Siefken 


\title{
Calculation of Hydrogen and Oxygen Uptake in Fuel Rod Cladding During Severe Accidents Using the Integral Diffusion Method Final Design Report
}

\author{
L. J. Siefken
}

Published May 1999

Idaho National Engineering and Environmental Laboratory Lockheed Martin Idaho Technologies Company Idaho Falls, Idaho 83415

Prepared for

Division of Systems Technology Office of Nuclear Regulatory Research

U.S. Nuclear Regulatory Commission

Washington, DC 20555-0001

NRC Job Code W6095 


\section{ABSTRACT}

Final designs are described for models of hydrogen and oxygen uptake in fuel rod cladding during severe accidents. Calculation of the uptake involves the modeling of seven processes: (1) diffusion of oxygen from the bulk gas into the boundary layer at the external cladding surface, (2) diffusion from the boundary layer into the oxide layer, (3) diffusion from the inner surface of the oxide layer into the metallic part of the cladding, (4) uptake of hydrogen in the event that the cladding oxide layer is dissolved in a steam-starved region, (5) embrittlement of cladding due to hydrogen uptake, (6) cracking of cladding during quenching due to its embrittlement and (7) release of hydrogen from the cladding after cracking of the cladding. An integral diffusion method is described for calculating the diffusion processes in the cladding. Experimental results are presented that show a rapid uptake of hydrogen in the event of dissolution of the oxide layer and a rapid release of hydrogen in the event of cracking of the oxide layer. These experimental results are used as a basis for calculating the rate of hydrogen uptake and the rate of hydrogen release. The uptake of hydrogen is limited to the equilibrium solubility calculated by applying Sievert's law. The uptake of hydrogen is an exothermic reaction that accelerates the heatup of a fuel rod. An embrittlement criteria is described that accounts for hydrogen and oxygen concentration and the extent of oxidation. A description is given of the implementation of the models for hydrogen and oxygen uptake and cladding embrittlement into the programming framework of the SCDAP/RELAP5/MOD3.3 code. The hydrogen and oxygen uptake models together with other early-phase damage progression models added to MOD3.3 were assessed using the results of several severe fuel damage tests. In general, the calculated behavior of the test bundles during the severe fuel damage tests was in good agreement with measured behavior. The capability of the integral diffusion model to calculate oxide layer thinning at locations with steam starvation was found to significantly improve the calculated axial distribution in the extent of cladding oxidation. This report is the final design version of the report with the identifier of INEEL/EXT-98-00664 Revision 1, entitled "Preliminary Design Report for Modeling of Hydrogen Uptake in Fuel Rod Cladding During Severe Accidents - Preliminary Design Report." 


\section{CONTENTS}

1. Introduction 1

2. Oxygen Transport and Dissolution of Oxide Layer ...........................................................

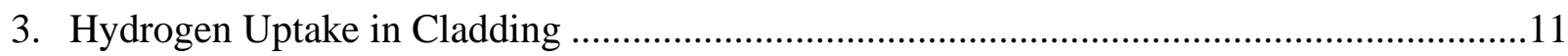

4. Cladding Embrittlement and Hydrogen Release ...............................................................

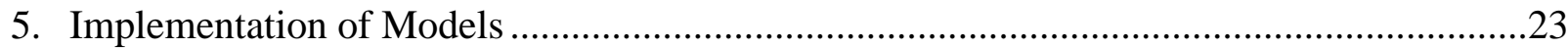

6. Assessment of Early-Phase Damage Progression Models .......................................................24

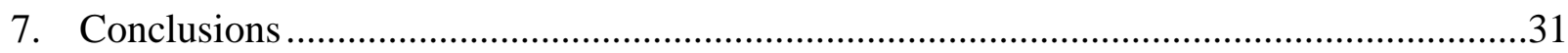

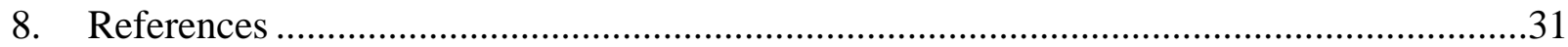

A1. Diffusion of Oxygen in Oxidic Layer.................................................................... A1-1

A2. Diffusion of Oxygen in Metallic Layer ……………................................................ A1-1

A3. Alternative Correlations for Diffusion of Oxygen in Oxidic and Metallic Layers....... A1-1

A4. Correlation for Binary Diffusivity in $\mathrm{H}_{2} \mathrm{O}+\mathrm{H}_{2}$ Mixture ........................................... A1-2

A5. Stoichiometry of Oxidic Surface …………………................................................ A1-2

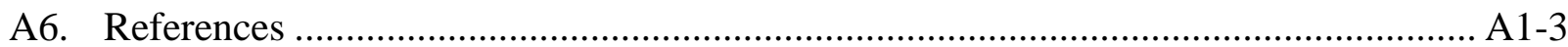

FIGURES

Figure 1. Radial distribution of oxygen in the bulk gas and in the cladding ............................2

Figure 2. Simplified $\mathrm{Zr}-\mathrm{O}$ phase diagram with homogenized oxide and metal phases. ..............3

Figure 3. Schematic of hydrogen uptake in cladding. ..........................................................12

Figure 4. Rate of hydrogen uptake as function of temperature as measured

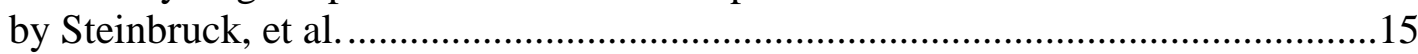

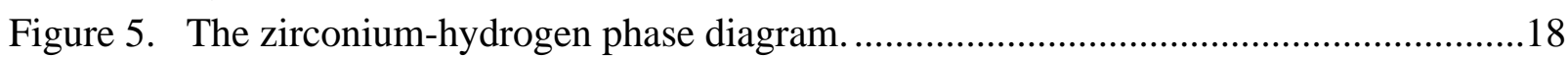

Figure 6. Crack formation in preoxidized Zircaloy during rapid cooldown from $1200 \mathrm{C}$ by steam.

Figure 7. Crack formation in preoxidized Zircaloy during rapid cooldown from $1400 \mathrm{C}$ by steam.

Figure 8. Temperature history and corresponding hydrogen release.....................................21

Figure 9. Implementation of $\mathrm{Zr}-\mathrm{H}$ interaction models into frame work

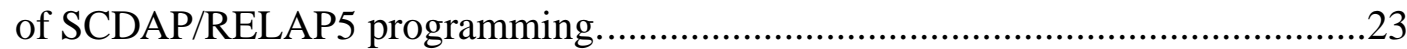

Figure 10. Calculated cladding oxide-thickness for PBF SFD 1-1 test at $0.75 \mathrm{~m}$ elevation..................25

Figure 11. Comparison of calculated and measured cladding temperature for PBF SFD 1-1 test at $0.35 \mathrm{~m}$...

Figure 12. Comparison of calculated and measured cladding temperature for PBF SFD 1-1 test at $0.5 \mathrm{~m}$. 
Figure 13. Comparison of calculated and measured cladding temperature for

PBF SFD 1-4 test at 0.39

Figure 14. Comparison of calculated and measured cladding temperature for

PBF SFD $1-4$ test at $0.54 \mathrm{~m}$

Figure 15. Comparison of calculated and measured cladding temperatures for

FzK CORA-7 test at $0.55 \mathrm{~m}$

Figure 16. Comparison of calculated and measured cladding temperature for

FzK CORA-7 test at $0.75 \mathrm{~m}$

Figure 17. Comparison of calculated and measured cladding temperature for NRU FLHT-5 test at $2.2 \mathrm{~m}$

Figure 18. Comparison of calculated and measured cladding temperature for NRU FLHT-5 test at $2.6 \mathrm{~m}$

\section{TABLES}

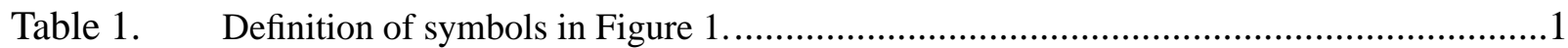

Table 2. Period of hydrogen uptake (parameter $t_{\text {eq }}$ ) as a function of temperature.....................15

Table 3. Conditions for example calculation of rate of heat generation

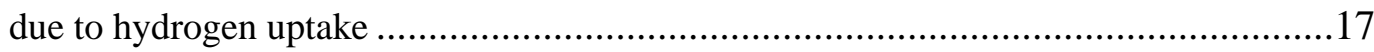

Table 4. Model for determining whether cladding is embrittled..........................................20

Table 5. Matrix of test problems for assessing models for $\mathrm{Zr}-\mathrm{H}$ interaction

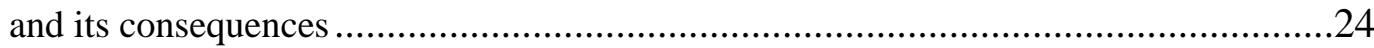

Table 6. Comparison of calculated and measured axial distribution in oxidation

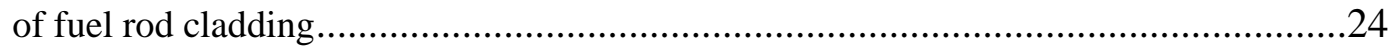

Table 7. Comparison of calculated and measured hydrogen production .................................26 


\section{Introduction}

Experimental and theoretical results have shown that the behavior of fuel rods during a severe accident may be significantly influenced by the uptake of hydrogen in the fuel rod cladding in the regions of the reactor core with a hydrogen-rich (steam-starved) environment. The uptake of $\mathrm{H}_{2}$ does not begin until the oxide layer dissolves into the metallic layer. This dissolution process results from a hydrogen-rich environment at the outer surface of the oxide layer. The uptake of hydrogen may cause a heatup of the cladding that is of the same order of magnitude as that caused by oxidation. The uptake of hydrogen may embrittle the fuel rod cladding and make it vulnerable to cracking during a core reflood. In a steam-rich environment, the cracking of the cladding results in a release of hydrogen from the cladding to the bulk fluid. SCDAP/RELAP5/MOD3.2 ${ }^{1}$ has no models for hydrogen uptake and hydrogen release or for evaluating the vulnerability to cracking caused by hydrogen uptake. Final designs for modeling these aspects of fuel rod behavior are described in this report.

This report is organized as follows. A model for calculating the time at which a $\mathrm{ZrO}_{2}$ layer may disappear due to dissolution of oxygen into the adjoining metallic layer is described in Section 2. This model applies the integral diffusion method to calculate the diffusion of oxygen from the bulk gas into the cladding oxide layer and then into the cladding metallic layer. Section 3 describes the model for calculating the rate of hydrogen uptake and the resulting heat generation following the disappearance of the oxide layer. A model for evaluating the vulnerability of the cladding to cracking due to embrittlement caused by hydrogen uptake is described in Section 4. This section also describes a model for calculating the rate of release of hydrogen after cracking of the cladding. A description of the implementation of the oxygen and hydrogen uptake models into the programming framework of SCDAP/RELAP5 is described in Section 5. The assessment of the oxygen and hydrogen uptake models together with other early-phase damage progression models added to MOD3.3 is presented in Section 6. Conclusions are presented in Section 7 and the references are listed in Section 8 .

\section{Oxygen Transport and Dissolution of Oxide Layer}

Hydrogen uptake occurs after the oxide layer at the cladding outer surface dissolves into its adjoining metallic layer. This event can happen when a relatively thin oxide layer exists in a steam-starved environment for a period of time. The calculation of this event in turn requires the calculation of the transport of oxygen from the bulk gas to the oxide layer and then from the oxide layer to the metallic layer. Figure 1 shows schematically the oxygen distribution in the gas boundary layer, cladding oxide layer, and cladding metallic layer. The symbols in Figure 1 are defined in Table 1. The context of

Table 1. Definition of symbols in Figure 1.

\begin{tabular}{|c|c|c|}
\hline Symbol & Units & Definition \\
\hline \hline$y_{i}$ & - & mole fraction of $\mathrm{H}_{2} \mathrm{O}$ in bulk gas at axial node $i$ \\
\hline$y_{s}$ & - & mole fraction of $\mathrm{H}_{2} \mathrm{O}$ in gas at outer surface of oxide layer \\
\hline$C_{s}$ & - & O/Zr ratio at external surface of oxide layer \\
\hline$C_{a}$ & - & $\begin{array}{c}\text { O/Zr ratio at inner surface of oxide layer; } 1.97 \leq C_{a} \leq 1.985 \text { for temperature } \\
\text { less than } 1773 \mathrm{~K}, \mathrm{C}_{a}=1.72 \text { for temperature greater than } 1773 \mathrm{~K} .\end{array}$ \\
\hline$C_{b}$ & - & O/Zr ratio at outer surface of metallic layer (terminal solubility) \\
\hline
\end{tabular}


Table 1. Definition of symbols in Figure 1.

\begin{tabular}{|c|c|c|}
\hline Symbol & Units & Definition \\
\hline \hline$\delta$ & $m$ & Thickness of oxide layer \\
\hline$\xi$ & $m$ & thickness of metallic layer \\
\hline$x$ & $m$ & spatial coordinate for oxide layer \\
\hline$x$ & $m$ & spatial coordinate for metallic layer \\
\hline
\end{tabular}

Figure 1 is single-sided oxidation, for which steam contacts the outer surface of the cladding but not its inner surface.

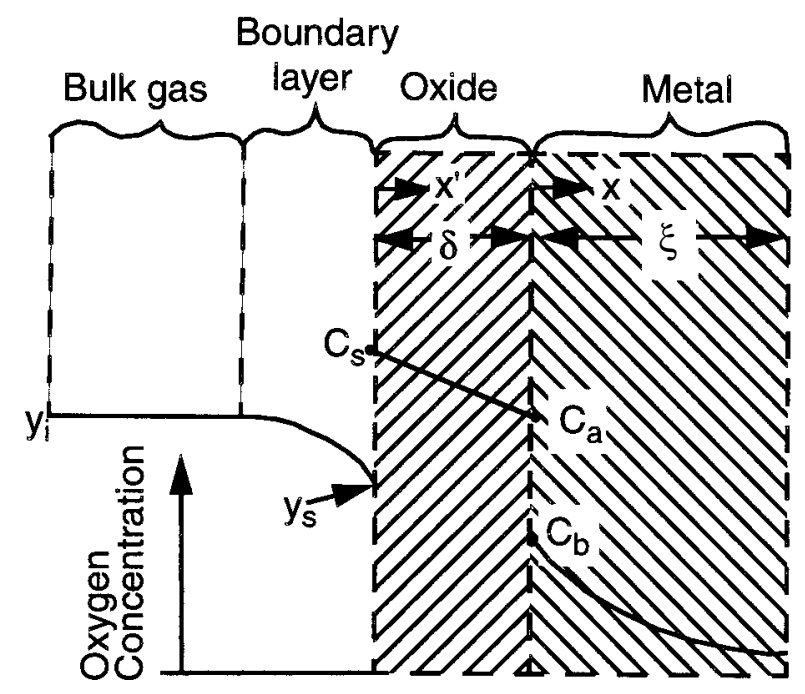

Figure 1. Radial distribution of oxygen in the bulk gas and in the cladding.

The overall oxygen transport is calculated by coupling the equations that calculate the diffusion of oxygen through the three layers shown in Figure 1. The integral diffusion method of solution as derived by Olander ${ }^{2}$ will be used. The distance of steam penetration into the fuel-cladding gap from the point of cladding rupture will be assumed to be negligible. Theoretical analyses and experimental results have shown that the distance of penetration is small compared to the overall length of fuel rods. ${ }^{3,17,18}$ Thus, the boundary condition for the inner surface of the cladding is defined simply to be that the gradient in oxygen concentration is equal to zero.

The oxygen transport is governed to a significant extent by the phase diagram for the $\mathrm{Zr}-\mathrm{O}$ system. Figure 2 shows the simplified phase diagram ${ }^{2}$ that will be employed. The symbols in this figure are the same as those defined in Table 1 . In a steam-rich environment, $\mathrm{C}_{\mathrm{s}}$ equals 2.00 and the outer surface is stoichiometric oxide $\mathrm{ZrO}_{2}$. In a steam-starved environment, $\mathrm{y}_{\mathrm{s}}$ may be small enough that $\mathrm{C}_{\mathrm{s}}$ is less than 2.00. When $\mathrm{C}_{\mathrm{s}}$ is reduced in value to the $\mathrm{O} / \mathrm{Zr}$ ratio of the lower phase boundary of zirconia $\left(\mathrm{C}_{\mathrm{s}}=\mathrm{C}_{\mathrm{a}}\right.$ as shown in Figure 2$)$, the oxide layer gradually dissolves into the metallic layer and eventually may completely disappear. When this occurs, hydrogen begins to diffuse into the metallic layer. 


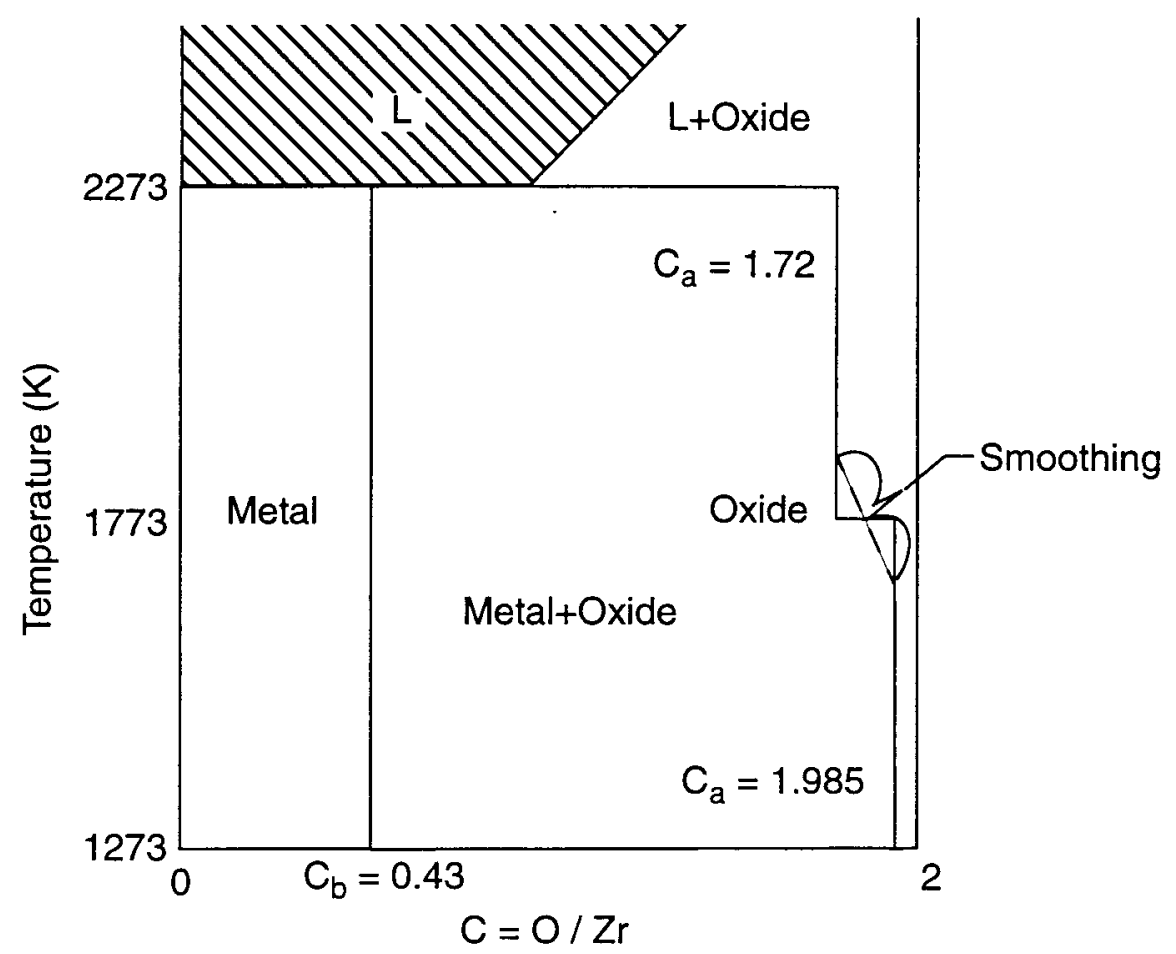

Figure 2. Simplified $\mathrm{Zr}-\mathrm{O}$ phase diagram with homogenized oxide and metal phases.

The equations for calculating the oxygen diffusion through the three layers shown in Figure 1 are described next.

The flux of water vapor through the gas boundary layer is calculated by the equation

$$
\dot{w}=k_{g} C_{g}\left(y_{i}-y_{s}\right)
$$

where

$\begin{array}{lll}\dot{w} & = & \text { mass flux of oxygen through the gas boundary layer }\left(\mathrm{kg}-\text { moles } / \mathrm{m}^{2} \cdot \mathrm{s}\right), \\ \mathrm{k}_{\mathrm{g}} & = & \text { mass transfer coefficient }(\mathrm{m} / \mathrm{s}), \\ \mathrm{C}_{\mathrm{g}} & = & \text { molar density of the bulk gas }\left(\mathrm{p}_{\mathrm{tot}} / \mathrm{RT}\right)\left(\mathrm{kg}-\mathrm{mole} / \mathrm{m}^{3}\right), \\ \mathrm{p}_{\text {tot }} & = & \text { total pressure of the bulk gas }(\mathrm{Pa}), \\ \mathrm{R} & = & \text { universal gas constant }\left(\mathrm{Pa} \cdot \mathrm{m}^{3} / \mathrm{kg}-\mathrm{mole} \cdot \mathrm{K}\right), \\ \mathrm{T} & = & \text { temperature of bulk gas }(\mathrm{K}), \\ \mathrm{y}_{\mathrm{i}} & = & \text { mole fraction of } \mathrm{H}_{2} \mathrm{O} \text { in the bulk gas at location of axial node } \mathrm{i}, \\ \mathrm{y}_{\mathrm{s}} & = & \text { mole fraction of } \mathrm{H}_{2} \mathrm{O} \text { in the gas at the cladding outer surface. }\end{array}$


The mass transfer coefficient $\mathrm{k}_{\mathrm{g}}$ is calculated using the analogy between heat and mass transfer. According to this analogy,

$$
\mathrm{k}_{\mathrm{g}}=\frac{\mathrm{NuD}_{\mathrm{g}}}{\mathrm{d}_{\mathrm{h}}}
$$

where

$\begin{array}{lll}\mathrm{Nu} & = & \text { Nusselt number of the bulk gas }\left(\frac{\mathrm{hd}_{\mathrm{h}}}{\mathrm{k}_{\mathrm{v}}}\right), \\ \mathrm{h} & = & \text { convective heat transfer coefficient }\left(\mathrm{W} / \mathrm{m}^{2} \cdot \mathrm{K}\right), \\ \mathrm{D}_{\mathrm{g}} & = & \text { binary diffusivity in } \mathrm{H}_{2} \mathrm{O}+\mathrm{H}_{2} \text { mixture }\left(\mathrm{m}^{2} / \mathrm{s}\right), \\ \mathrm{d}_{\mathrm{h}} & = & \text { hydraulic diameter, }\left(\mathrm{s}^{2}-\pi r_{o}^{2}\right) /\left(2 \pi r_{o}\right),(\mathrm{m}), \\ \mathrm{k}_{\mathrm{V}} & = & \text { thermal conductivity of the bulk gas }(\mathrm{W} / \mathrm{m} \cdot \mathrm{K}), \\ \mathrm{S} & = & \text { pitch of the fuel rods }(\mathrm{m}), \\ r_{o} & = & \text { outer radius of rods }(\mathrm{m}) .\end{array}$

The heat and mass transfer analogy is valid provided that the Prandtl number is approximately equal to the Schmidt number for the gas mixture. ${ }^{16}$ For the wide range in coolant pressures and temperatures that are possible during a severe accident, wide variations in Prandtl number and Schmidt number occur. For some range of conditions, these two numbers may vary significantly from each other and result in a loss of accuracy in the mass transfer calculation. However, the oxidation of fuel rods is generally not limited by the rate of mass transfer through the boundary layer and the Prandtl and Schmidt numbers are not expected to have a large variance for extended periods of time over a large region of the reactor core. Therefore, the heat and mass transfer analogy is still an appropriate analysis tool to apply.

The variable $\mathrm{D}_{\mathrm{g}}$ will be calculated by the model for mass diffusivity that is currently in SCDAP/ RELAP5 ${ }^{1}$. This model is applicable to gas mixtures composed of several species. An alternative model for a mixture of $\mathrm{H}_{2} \mathrm{O}$ and $\mathrm{H}_{2}$ is presented in Appendix A.

The diffusion of oxygen through the gas boundary layer and then through the oxide layer can be regarded as two steps in series. Thus, diffusion through the two layers is equal and expressed by the equation

$$
\dot{\mathrm{w}}=\rho_{\mathrm{ox}} \mathrm{D}_{\mathrm{ox}}\left(\mathrm{C}_{\mathrm{s}}-\mathrm{C}_{\mathrm{a}}\right) / \delta
$$

where

$$
\begin{array}{lll}
\rho_{\mathrm{ox}} & = & \text { molar density of } \mathrm{Zr} \text { in } \mathrm{ZrO}_{2}\left(\mathrm{~kg}-\mathrm{mole} / \mathrm{m}^{3}\right)\left(47 \mathrm{~kg}-\mathrm{mole} / \mathrm{m}^{3}\right), \\
\mathrm{D}_{\mathrm{ox}} & = & \text { diffusion coefficient of oxygen in the oxide layer }\left(\mathrm{m}^{2} / \mathrm{s}\right) .
\end{array}
$$

The correlation to be used for $\mathrm{D}_{\mathrm{ox}}$ is given in Appendix A. The linear profile in oxygen concentration and the steady state modeling of mass transfer implied by Equation (3) have been shown to incur errors of 
less than $1 \%$ in the calculated oxygen uptake ${ }^{2}$. The small error in calculation is due to the driving force $\left(\mathrm{C}_{\mathrm{s}}-\mathrm{C}_{\mathrm{a}}\right)$ being a small fraction of $\mathrm{C}_{\mathrm{a}}$.

The value of $\mathrm{C}_{\mathrm{s}}$ in Equation (3) is very close to the value of 2.0 as long as the gas at the cladding surface contains at least a small fraction of water vapor ${ }^{2}$. Thus, for usual applications, Equations (1) and (3) can be combined to give

$$
y_{s}=y_{i}-\frac{D_{o x} \rho_{o x}\left(2-C_{a}\right)}{k_{g} C_{g} \delta} .
$$

The value of $\mathrm{C}_{\mathrm{s}}$ is a function of temperature and the partial pressures of steam and hydrogen in the gas adjacent to the cladding surface. This function is described in Appendix A. A study applying this functional relation for $\mathrm{C}_{\mathrm{s}}$ will be performed to determine how sensitive calculation results are to the value of $\mathrm{C}_{\mathrm{s}}$.

When $\mathrm{y}_{\mathrm{s}}$ as calculated by Equation (4) is negative, then the oxygen uptake is limited to the flux through the gas boundary layer as given by Equation (1) with $\mathrm{y}_{\mathrm{s}}$ equal to 0.0. Thus for this condition, $\mathrm{C}_{\mathrm{s}}$ is given by the equation

$$
\mathrm{C}_{\mathrm{s}}=\mathrm{C}_{\mathrm{a}}+\frac{\mathrm{k}_{\mathrm{g}} \mathrm{C}_{\mathrm{g}} \mathrm{y}_{\mathrm{i}} \delta}{\rho_{\mathrm{ox}} \mathrm{D}_{\mathrm{ox}}} .
$$

The overall mass balance on zirconium is given by the equation

$$
\xi_{\mathrm{O}}=\xi_{1}+\mathrm{G} \delta_{\mathrm{O}}=\xi+\mathrm{G} \delta
$$

where

$$
\begin{array}{lll}
\xi_{\mathrm{O}} & = & \text { as-fabricated thickness of cladding }(\mathrm{m}), \\
\xi_{1} & = & \text { thickness of metallic layer at time of } 0.0(\mathrm{~m}), \\
\delta_{\mathrm{O}} & = & \text { thickness of oxide layer at time of } 0.0(\mathrm{~m}), \\
\xi & = & \text { thickness of metallic layer at time of } \mathrm{t}(\mathrm{m}), \\
\delta & = & \text { thickness of oxide layer at time of } \mathrm{t}(\mathrm{m}), \\
\mathrm{G}^{-1} & = & \text { Pilling-Bedworth ratio of } \mathrm{ZrO}_{2}(\mathrm{G}=0.67) .
\end{array}
$$

Oxygen transport in the metallic layer is governed by Fick's law, with a convective term that accounts for the moving oxide-metal interface. Fick's law is expressed by the equation

$$
\frac{\partial c}{\partial t}=D_{m} \frac{\partial^{2} c}{\partial x^{2}}+G \frac{d \delta}{d t} \frac{\partial c}{\partial x}
$$

where

$\mathrm{c}=\mathrm{O} / \mathrm{Zr}$ ratio in the metallic layer at time $\mathrm{t}$ and at radial coordinate $\mathrm{x}$, 


$\begin{array}{lll}\mathrm{x} & = & \text { distance from moving interface, as shown in Figure 1(m), } \\ \mathrm{t} & = & \text { time }(\mathrm{s}), \\ \mathrm{D}_{\mathrm{m}} & = & \text { diffusion coefficient of oxygen in } \alpha-\mathrm{Zr}\left(\mathrm{m}^{2} / \mathrm{s}\right) .\end{array}$

The initial and boundary conditions for the above equation are

$\mathrm{c}(\mathrm{x}, \mathrm{o})=\mathrm{c}_{\mathrm{o}}$

where

$$
\begin{aligned}
& \mathrm{c}_{\mathrm{o}} \quad \text { oxygen concentration in as-fabricated Zircaloy. } \\
& \mathrm{c}(\mathrm{o}, \mathrm{t})=\mathrm{C}_{\mathrm{b}} \\
& \frac{\partial \mathrm{c}(\xi, \mathrm{t})}{\partial \mathrm{x}}=0.0
\end{aligned}
$$

The boundary condition applied in Equation (10) is based on the assumption that the rate of oxygen entering the cladding at the inner surface is negligible. If the fuel and cladding are not forced into contact and the location is more than a few $\mathrm{cm}$ from the point of cladding rupture, this assumption is justified ${ }^{3}$. The boundary condition is appropriate for cladding that has ballooned but not melted.

The analysis of a melted metallic layer in contact with an oxide layer $\left(\mathrm{ZrO}_{2}\right)$ on one side and fuel $\left(\mathrm{UO}_{2}\right)$ on the other side is an extension in modeling that goes beyond the scope of this report. A framework for this extension is established by the modeling presented in this report. In order to accomplish this extension, the boundary condition represented by Equation (10) needs to define the oxygen flux at the dissolution front in the fuel. Boundary conditions at moving positions would be required at both sides of the melted $\mathrm{Zr}$ layer. The mass diffusion in the fuel would need to be calculated, and an account made of the effect of dissolved $\mathrm{UO}_{2}$ on the diffusion in the metallic layer. While this extension requires considerable modeling effort, it has the virtue of accounting for the effect of $\mathrm{UO}_{2}$ dissolution on $\mathrm{ZrO}_{2}$ dissolution.

The correlation to be used for $\mathrm{D}_{\mathrm{m}}$ in Equation (7) is given in Appendix A.

The integral diffusion method is applied by integrating Equation (7) with respect to $x$ over the thickness of the metallic layer. The integration is performed over the domain $(0<\mathrm{x}<\xi)$. The result of this integration is

$$
\frac{\mathrm{d}}{\mathrm{dt}}(\xi \overline{\mathrm{c}})=\mathrm{D}_{\mathrm{m}}\left[\left(\frac{\partial \mathrm{c}}{\partial \mathrm{x}}\right)_{\xi}-\left(\frac{\partial \mathrm{c}}{\partial \mathrm{x}}\right)_{0}\right]+\mathrm{G} \frac{\mathrm{d} \delta}{\mathrm{dt}}\left[\mathrm{c}(\xi, \mathrm{t})-\mathrm{C}_{\mathrm{b}}\right]
$$

where

$$
\overline{\mathrm{c}} \quad=\quad \text { average } \mathrm{O} / \mathrm{Zr} \text { ratio in the metallic layer. }
$$

The variable $\bar{c}$ is calculated by the equation 
$\overline{\mathrm{c}}=\frac{1}{\xi} \int_{0}^{\xi} \mathrm{c}(\mathrm{x}, \mathrm{t}) \mathrm{dx}$.

Equation (11) is converted to an ordinary differential equation by choosing an approximate distribution $\mathrm{c}(\mathrm{x}, \mathrm{t})$ that automatically satisfies the boundary conditions as expressed by Equations (9) and (10) and contains a single time-dependent parameter whose value at $t=0$ is chosen to satisfy the initial conditions as expressed by Equation (8). Such an approximate distribution is given by the function

$\mathrm{c}=\mathrm{C}_{\mathrm{b}} \frac{\exp ((-\phi / \mathrm{E})+\exp \{-(1-\phi) / E\})}{1+\exp (-1 / \mathrm{E})}$

$\phi=\frac{x}{2 \xi} \quad 0 \leq \phi \leq \frac{1}{2}$

The substitution of Equation (13) into Equation (11) results in the equation for calculating the rate of change of the average $\mathrm{O} / \mathrm{Zr}$ ratio in the metallic layer. The result of this substitution is;

$\frac{d}{d t}\left(\frac{\bar{c}}{c_{b}}\right)=\frac{D_{m}}{(2 E \xi)^{2}}\left(\frac{\bar{c}}{c_{b}}\right)-\frac{G}{\xi}\left[1-\frac{2 \exp \left(-\frac{1}{2 E}\right)}{1+\exp \left(-\frac{1}{E}\right)}\right]$

The variable $\mathrm{E}$ is a function of time and it is evaluated by the relationship between $\mathrm{E}$ and the average $\mathrm{O} / \mathrm{Zr}$ ratio in the metallic layer. This relationship is obtained by substituting Equation (13) into Equation (12). The result of this substitution is

$\frac{\overline{\mathrm{c}}}{\mathrm{C}_{\mathrm{b}}}=2 \mathrm{E} \frac{1-\exp (-1 / \mathrm{E})}{1+\exp (-1 / \mathrm{E})}$

The rate of movement of the inside surface of the oxide layer is equal to the difference between the oxygen flux on the outside surface of the metallic layer and the oxygen flux on the inside surface of the oxide layer. This relation is expressed by the equation

$\rho_{\text {ox }}\left(C_{a}-C_{b}\right) \frac{d \delta}{d t}=\rho_{M} D_{M}\left(\frac{\partial c}{\partial x}\right)_{o}-\rho_{o x} D_{o x}\left(\frac{\partial c^{\prime}}{\partial x^{\prime}}\right)_{\delta}$

where

$\left(\frac{\partial \mathrm{c}}{\partial \mathrm{x}}\right)_{\mathrm{o}}=\quad \mathrm{O} / \mathrm{Zr}$ gradient in the metallic layer at its interface with the oxide layer,
$\left(\frac{\partial \mathrm{c}^{\prime}}{\partial \mathrm{x}^{\prime}}\right)_{\delta}=\quad \mathrm{O} / \mathrm{Zr}$ gradient in the oxide phase at its interface with the metallic layer, 
$\rho_{\mathrm{m}} \quad=\quad$ molar density of $\mathrm{Zr}$ in the metallic layer $\left(\mathrm{kg}-\mathrm{mole} / \mathrm{m}^{3}\right)$.

The value of $\rho_{\mathrm{m}}$ is given by the equation

$\rho_{\mathrm{m}}=\rho_{\mathrm{O}_{\mathrm{X}}} / \mathrm{G}=\rho_{\mathrm{O}_{\mathrm{X}}} / 0.67$

The oxygen concentration distribution in the oxide layer is assumed to be linear. Thus the variable $\left(\partial c^{\prime} / \partial x^{\prime}\right)_{\delta}$ in Equation (16) is given by the equation

$\left(\frac{\partial \mathrm{c}^{\prime}}{\partial \mathrm{x}^{\prime}}\right)_{\delta}=\left(\mathrm{C}_{\mathrm{a}}-\mathrm{C}_{s}\right) / \delta$

Substituting Equation (18) into Equation (16), replacing $\rho_{\mathrm{m}}$ with its equivalent of $\rho_{\mathrm{ox}} / \mathrm{G}$, and evaluating the oxygen concentration gradient at $\mathrm{x}=0$ in Equation (16) using Equation (13) yields the equation

$\mathrm{G}\left(\mathrm{C}_{\mathrm{a}}-\mathrm{C}_{\mathrm{b}}\right) \frac{\mathrm{d} \delta}{\mathrm{dt}}=-\frac{\mathrm{D}_{\mathrm{m}} \mathrm{C}_{\mathrm{b}}}{4 \mathrm{E}^{2} \xi}\left(\frac{\overline{\mathrm{c}}}{\mathrm{C}_{\mathrm{b}}}\right)+\frac{\mathrm{GD}_{\mathrm{ox}}}{\delta}\left(\mathrm{C}_{\mathrm{s}}-\mathrm{C}_{\mathrm{a}}\right)$

Equations (19), (6), (11), and (15) are a coupled set of equations for solving for the unknown variables $\delta, \xi$, $\overline{\mathrm{c}}$, and $\mathrm{E}$, respectively.

The calculated value of $\delta$ is used to determine whether the $\mathrm{Zr}-\mathrm{H}$ reaction begins in the cladding. If $\delta$ is greater than zero, then the oxide layer insulates the metallic layer from the hydrogen in the bulk gas. If $\delta$ is equal to zero, then hydrogen diffuses into the metallic layer.

The integral solution method will next be presented for calculating oxygen transport in the other two possible states of the cladding, namely the state of no oxide layer being present and the state of no metallic layer being present. With the description of the solution for these states, the integral method is shown to be applicable to all possible states of the cladding.

In the event that the oxide layer has dissolved completely into the metallic layer and is no longer present, the oxygen transport in the metallic layer is then governed by the equation

$$
\frac{\partial c}{\partial t}=D_{m} \frac{\partial^{2} c}{\partial x^{2}} \text {. }
$$

The boundary condition for Equation (20) at the outer surface of the metallic layer is the oxygen flux through the gas phase boundary. This boundary condition is expressed by the equation

$$
\mathrm{k}_{\mathrm{g}}\left[C_{g} \mathrm{y}_{\mathrm{i}}-c(o, t)\right]=-\mathrm{D}_{\mathrm{M}} \rho_{\mathrm{M}}\left(\frac{\partial \mathrm{c}}{\partial \mathrm{x}}\right)_{0}
$$

The absence of the oxide layer is assumed to imply a steam-starved interface. Thus, $c(o, t)=0.0$. 
At the inner surface of the metallic layer, the zero flux condition applies, i.e.

$$
\left(\frac{\partial c}{\partial x}\right)_{\xi_{o}}=0
$$

The initial condition for Equation (20) is the oxygen distribution in the metallic layer at the time that the oxide layer just disappeared. The integral method will also be applied to solve for Equation (20). The approximate distribution in oxygen as defined by Equation (13) is adopted for the solution of Equation (20) with the terminal oxygen solubility at the outer surface of the metallic layer (variable $C_{b}$ in Equation (13)) replaced by the undetermined function $\mathrm{c}(0, \mathrm{t})$ :

$c=c(0, t) \frac{\exp (-\phi / E)+\exp \{-(1-\phi) / E\}}{1+\exp (-1 / E)}$

where

$$
\phi=\frac{\mathrm{x}}{2 \xi_{\mathrm{O}}} \quad 0 \leq \phi \leq \frac{1}{2} .
$$

The average oxygen concentration in the metallic phase is thus given by the equation

$$
\frac{\overline{\mathrm{c}}}{\mathrm{c}(0, \mathrm{t})}=2 \mathrm{E} \frac{1-\exp (-1 / \mathrm{E})}{1+\exp (-1 / \mathrm{E})}
$$

Substituting the approximate oxygen distribution as given by Equation (24) into Equation (21) and using Equation (24) to eliminate the surface concentration fixes the parameter E according to

$$
E=\left\{\frac{D_{M} \rho_{M} C_{b}}{4 \xi_{o} k_{g} C_{g} y_{i}}\left(\frac{\bar{c}}{C_{b}}\right)\right\}^{1 / 2} .
$$

The concentration of oxygen at the external surface of the metallic layer can be determined by solving Equation (24) for $\mathrm{c}(0, \mathrm{t})$. The result is

$$
\frac{c(0, t)}{C_{b}}=\frac{\left(\bar{c} / C_{b}\right)}{2 E} \frac{1+\exp (-1 / E)}{1-\exp (-1 / E)}
$$

Finally, the integration of Equation (20) with respect to $x$ over the domain $\left(0<x<\xi_{0}\right)$ results in the equation

$$
\frac{d}{d t}\left(\frac{\bar{c}}{C_{b}}\right)=\frac{k_{g} C_{g} y_{i}}{\rho_{M} \xi_{o} C_{b}}
$$

Equations (25) and (27) are a set of two coupled equations for solving for the two variables $\mathrm{E}$ and $\bar{c}$, respectively. Equation (26) is also applied at each time step to determine whether the surface concentration $c(o, t)$ has returned to the terminal solubility $C_{b}$. If the value of the right hand side of Equation (26) is greater than unity, then $\mathrm{c}(\mathrm{o}, \mathrm{t})$ has exceeded the surface solubility and the oxide layer forms again. 
The case of an oxide layer propagating to the inner surface of the cladding is presented next. The time at which the oxide layer propagates to the inner surface is designated by the symbol $\mathrm{t}_{\mathrm{sw}}$. The average $\mathrm{O} / \mathrm{Zr}$ ratio in the oxide layer and the oxygen concentration gradient through the oxide layer are given by the equations

$$
\begin{aligned}
& \bar{c}^{\prime}=\frac{1}{2}\left(C_{s}+C_{a}\right), \\
& \frac{d c^{\prime}}{d x^{\prime}}=-\frac{C_{s}-C_{a}}{\xi_{o} / G} .
\end{aligned}
$$

For $\mathrm{t}>\mathrm{t}_{\mathrm{sw}}$, the oxygen concentration distribution through the oxide layer is no longer linear. The gradient of the oxygen concentration distribution at the inner surface of the cladding is given by the equation

$$
\left(\frac{\partial c^{\prime}}{\partial x^{\prime}}\right)_{\xi_{o} / G}=0
$$

To track the approach of the oxide layer to complete conversion to stoichiometric $\mathrm{ZrO}_{2}$, the oxygen concentration distribution through the oxide layer is assumed to be approximated by the following function:

$$
c^{\prime}=C_{s}-a\left(\eta+\frac{1}{2} \eta^{2}-\frac{2}{3} \eta^{3}\right)
$$

where

$$
\eta \quad=\quad \frac{x^{\prime}}{\xi_{o} / G}
$$

The polynomial function in Equation (31) has only one minimum for positive values of $\eta$, and that occurs at $\eta=1$, thereby satisfying Equation $(30)^{2}$.

In Equation (31), the variable " $a$ " is a function of time that is to be determined. Equation (31) has only one minimum for positive values of $\eta$, and that occurs at $\eta=1$, which results in the boundary condition for the inner surface of the cladding being satisfied as expressed by Equation (30).

The average oxygen concentration in the oxide layer as given by Equation (31) is given by the equation

$$
\overline{\mathrm{c}}^{\prime}=\int_{0}^{1} \mathrm{c}^{\prime} \mathrm{d} \eta=\mathrm{C}_{\mathrm{s}}-\frac{1}{2} \mathrm{a}
$$

The gradient in the oxygen concentration at the outer surface of the oxide layer is given by the equation

$$
\left(\frac{\mathrm{dc}^{\prime}}{\mathrm{dn}}\right)_{n}=-\mathrm{a}
$$


Equation (33) satisfies Equation (29) when the function a(t) at time $\mathrm{t}_{\mathrm{sw}}$ has the following value;

$a\left(\mathrm{t}_{\mathrm{sw}}\right)=\mathrm{C}_{\mathrm{s}}-\mathrm{C}_{\mathrm{a}}$.

Oxygen diffusion in the oxide layer is governed by Fick's law as expressed by the equation

$$
\frac{\partial \mathrm{c}^{\prime}}{\partial \mathrm{t}}=\mathrm{D}_{\mathrm{ox}} \frac{\partial^{2} \mathrm{c}^{\prime}}{\partial \mathrm{x}^{\prime 2}}
$$

Equation (35) can be integrated with respect to $x^{\prime}$ over the domain of the cladding thickness $\left(0<x^{\prime}<\left(\xi_{0} / G\right)\right)$. The oxygen concentration gradients at the inner and outside surfaces of the oxide layer are calculated from Equations (30) and (33), respectively. The result is an ordinary differential equation for the variable $a(t)$, which is expressed by the equation

$$
\frac{\mathrm{da}}{\mathrm{dt}}=\frac{2 \mathrm{D}_{\mathrm{ox}}}{\left(\xi_{\mathrm{o}} / \mathrm{G}\right)^{2}} \mathrm{a} \quad \mathrm{t} \geq \mathrm{t}_{\mathrm{sw}} .
$$

The initial condition for Equation (36) is given by Equation (34). Since the variable $\mathrm{D}_{\mathrm{ox}}$ varies with temperature and thus in severe accident conditions varies with time, Equation (36) cannot be directly integrated and instead must be solved numerically.

The oxygen uptake rate is determined from the solution of Equation (36) in conjunction with

$$
\dot{\mathrm{w}}=-\rho_{\mathrm{ox}} \mathrm{D}_{\mathrm{ox}}\left(\frac{\partial \mathrm{c}^{\prime}}{\partial \mathrm{x}^{\prime}}\right)_{0}=-\frac{\rho_{\mathrm{ox}} \mathrm{D}_{\mathrm{ox}}}{\xi_{\mathrm{o}} / \mathrm{G}}\left(\frac{\mathrm{dc} \mathrm{c}^{\prime}}{\mathrm{d} \eta^{\prime}}\right)_{0}=\frac{\rho_{\mathrm{ox}} \mathrm{D}_{\mathrm{ox}}}{\xi_{\mathrm{o}} / \mathrm{G}} \mathrm{a}
$$

A complete set of equations have now been expressed for calculating oxygen diffusion through the cladding for the three possible phase states of the cladding.

The integral method for calculating oxygen uptake is more accurate than the parabolic kinetics method for the case of steam starvation and transient temperature. ${ }^{2}$ Since the integral method is necessary for calculating the time at which hydrogen uptake begins, its implementation for this purpose also results in a complete calculation of cladding oxidation. Thus, the option exists for replacing the existing parabolic kinetics modeling of cladding oxidation with the integral solution method. As described further in Section 5 , an input option will be implemented that provides the capability to compare the accuracy and robustness of these two methods of solution.

\section{Hydrogen Uptake in Cladding}

The disappearance of the cladding oxide layer in a region of the reactor core with hydrogen-rich fluid results in the diffusion of hydrogen into the cladding. The calculation of the time that the oxide layer may disappear has been presented in Section 2. This section presents a set of equations that can be solved to calculate the uptake of hydrogen in the cladding. Equations are also presented for calculating the effect of hydrogen uptake on fuel rod heatup.

A simplified approach for calculating the rate of hydrogen uptake is used that capitalizes on the numerical results of detailed calculations. A schematic of the modeling of hydrogen uptake in the cladding 
is shown in Figure 3. A detailed modeling of hydrogen uptake involves the coupling of several
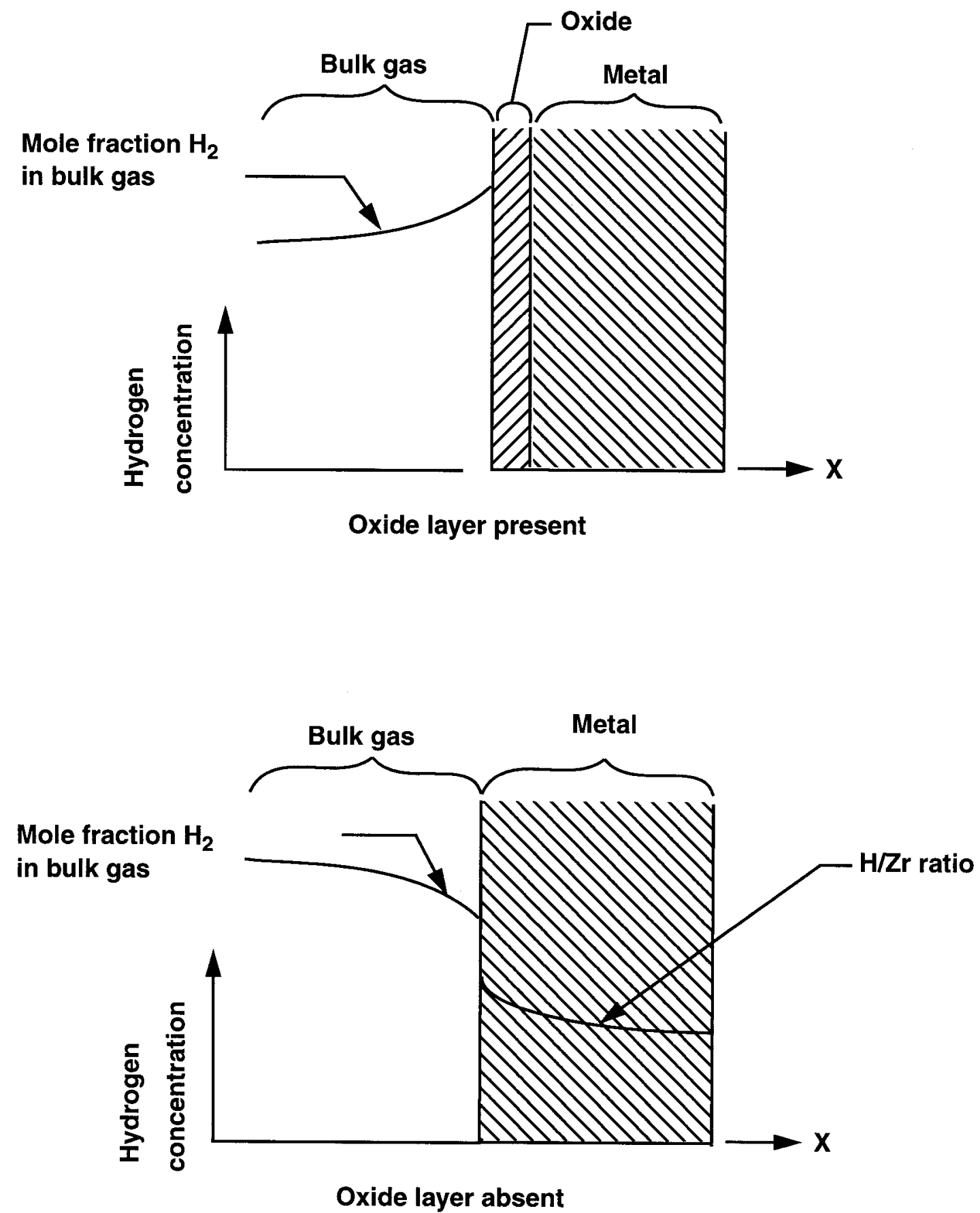

Figure 3. Schematic of hydrogen uptake in cladding.

phenomena; (1) diffusion of hydrogen from the fluid adjoining the external surface of the cladding through the cladding and into the fuel-cladding gap, (2) ternary diffusion of a mixture of $\mathrm{Xe}, \mathrm{He}$, and $\mathrm{H}_{2}$ in the axial direction through the fuel-cladding gap and then through the breach in the cladding caused by cladding rupture, (3) release from fuel of $\mathrm{Xe}$, and (4) diffusion of $\mathrm{He}$ from the upper fuel rod plenum into the fuel-cladding gap ${ }^{3}$. Calculations have shown that the hydrogen uptake occurs rapidly until the 
equilibrium solubility of the cladding is attained. In a calculation with conditions typical of a severe accident, the hydrogen uptake to the equilibrium solubility occurred in about $50 \mathrm{~s}^{3}$. This period of time is small compared with the period of time for evolution of the important damage progression events occurring during a severe accident. The rate of hydrogen permeation of the cladding was calculated to be much greater than the rate of diffusion of hydrogen from the breach site. Also, the amount of hydrogen that can be absorbed by the fuel-cladding gap is small compared to the amount of hydrogen that can be absorbed by the cladding. In view of the short time period for hydrogen uptake and in view of the small amount of hydrogen absorption and diffusion in the fuel-cladding gap, the modeling of the axial diffusion of hydrogen through the fuel-cladding gap and then its diffusion out of the breach site is not justified. Therefore, a simplified approach to calculating hydrogen uptake will be taken. If assessment indicates that this simplified approach is not justified, then an integral diffusion method similar to that used for oxygen uptake can be implemented.

The equilibrium solubility of hydrogen in the Zircaloy is assumed to be governed by Severities law ${ }^{4}$. According to Sievert's law for $\mathrm{Zr}-\mathrm{H}$ interaction, the equilibrium solubility is given by the equation

$$
C_{H}=A_{S H} \exp \left(-\frac{\Delta H_{H}}{R T}\right)\left(p_{H_{2}}\right)^{0.5}
$$

where

$$
\begin{aligned}
& \mathrm{C}_{\mathrm{H}}=\mathrm{H} / \mathrm{Zr} \text { ratio of the metal in equilibrium with the gas containing } \mathrm{H}_{2} \\
& \text { at a pressure of } p_{\mathrm{H} 2} \text {, } \\
& \mathrm{A}_{\mathrm{SH}} \quad=\quad \text { Sievert's law constant, } \\
& \Delta H_{H}=\text { enthalpy of solution }(\mathrm{kcal} / \mathrm{mol}) \text {, } \\
& \mathrm{R}=\quad \text { universal gas constant }(1.987 \mathrm{cal} / \mathrm{mole} \cdot \mathrm{K}) \text {, } \\
& \mathrm{T}=\quad \text { temperature of cladding }(\mathrm{K}) \text {, } \\
& \mathrm{p}_{\mathrm{H} 2}=\quad \text { partial pressure of hydrogen }(\mathrm{atm}) \text {. }
\end{aligned}
$$

Sievert's law constant is given by the equation ${ }^{4}$

$$
A_{S H}=e^{\Delta S / R}
$$

where

$$
\Delta S \quad=\quad \text { entropy of solution of hydrogen in zirconium }(\mathrm{cal} / \mathrm{mol} \cdot \mathrm{K}) .
$$

According to experimental results obtained by Moalem and Olander ${ }^{4}$, the entropies and enthalpies of solution of hydrogen in zirconium vary somewhat with the oxygen content and the phase ( $\alpha$ or $\beta$ ) of the zirconium. Representative values for severe accident analysis are:

$$
\Delta S=-12.5 \mathrm{cal} / \mathrm{mol} \cdot \mathrm{K}
$$


and

$\Delta H_{H}=-13.1 \mathrm{Kcal} / \mathrm{mol}$.

Since the enthalpy of solution $\left(\Delta H_{H}\right)$ is negative, the $\mathrm{Zr}-\mathrm{H}_{2}$ reaction is exothermic and thus causes an increase in the heatup of the cladding.

Substituting the values $\Delta S$ and $\Delta H$ given by Equations (40) and (41) into Equations (39) and (38) results in the following equation for $\mathrm{C}_{\mathrm{H}}$ :

$C_{H}=1.85 \times 10^{-3} \exp (6593 / T)\left(p_{H 2}\right)^{0.5}$.

For cladding at a temperature of $2000 \mathrm{~K}$ and a hydrogen pressure of $0.1 \mathrm{MPa}(1 \mathrm{~atm})$, the value of $\mathrm{C}_{\mathrm{H}}$ as calculated by Equation (42) is 0.05 . For cladding at a temperature of $2000 \mathrm{~K}$ and a hydrogen pressure of $3 \mathrm{MPa}(30 \mathrm{~atm})$, the value of $\mathrm{C}_{\mathrm{H}}$ is 0.27 . For cladding at a temperature of $1273 \mathrm{~K}$ and a hydrogen pressure of $0.1 \mathrm{MPa}(1 \mathrm{~atm})$, the value of $\mathrm{C}_{\mathrm{H}}$ is 0.33 .

The rate of hydrogen uptake after disappearance of the oxide layer is based on Olander's numerical results $^{3}$ and not upon mechanistic modeling. According to Olander's numerical results, the hydrogen uptake for conditions of a typical severe accident attains an equilibrium level in $\sim 50 \mathrm{~s}$. This calculated rate of hydrogen uptake is consistent with the rate of hydrogen uptake measured by Steinbruck, et al. ${ }^{5}$ The hydrogen uptake is assumed to follow a parabolic kinetics rule. Thus, the rate of hydrogen uptake is assumed to be given by the equation:

$\frac{d w_{h}}{d t}=\frac{K_{h}(T)}{w_{h}}$

where

$$
\begin{array}{ll}
\mathrm{w}_{\mathrm{h}}= & \begin{array}{l}
\text { uptake of hydrogen (ratio of hydrogen concentration in cladding to hydrogen } \\
\text { concentration at equilibrium level), }
\end{array} \\
\mathrm{K}_{\mathrm{h}}(\mathrm{T})= & \begin{array}{l}
\text { parabolic kinetics constant for uptake of hydrogen, which is a function of tem- } \\
\text { perature }(1 / \mathrm{s}),
\end{array} \\
\mathrm{t} & =\text { time }(\mathrm{s}) .
\end{array}
$$

The initial condition for Equation (43) is

$w_{h}\left(t_{d i s}\right)=0.0$

For analysis of hydrogen uptake during isothermal conditions, the value of $K(T)$ does not change with time. Thus, Equation (43) can be integrated to give

$w_{h}=\left[2 K_{h}\left(t-t_{d i s}\right)\right]^{0.5}$ 
where

${ }^{t}{ }_{\text {dis }} \quad=\quad$ time at which the oxide layer on the external cladding surface disappeared $(\mathrm{s})$.

At the equilibrium concentration of hydrogen, $\mathrm{C}_{\mathrm{H}}$, the value of $\mathrm{w}_{\mathrm{h}}$ is one.

The time to attain an equilibrium level of hydrogen concentration is assumed to be $t_{e q}$. Substituting these values into Equation (45) and solving for $\mathrm{K}_{\mathrm{h}}$, the result is:

$K_{h}(T)=\frac{1}{2 t_{e q}}$.

The value $t_{\mathrm{eq}}$ is a function of temperature. The approximate dependence of $t_{\mathrm{eq}}$ on temperature has been investigated by Steinbruck, et al. ${ }^{5}$ Figure 4 is a plot of the rate of hydrogen uptake as a function of

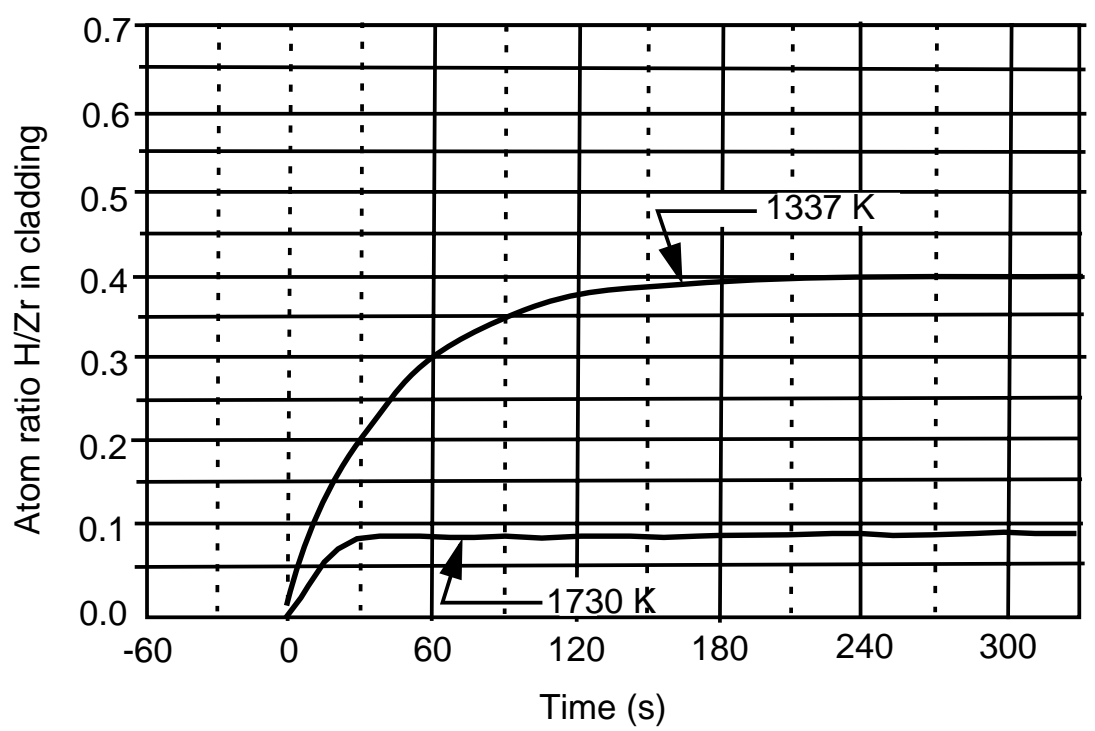

Figure 4. Rate of hydrogen uptake as function of temperature as measured by Steinbruck, et al.

temperature as measured by Steinbruck, et al. The approximate value of $t_{\mathrm{eq}}$ as indicated by the experimental results is shown in Table 2 . For cladding at a temperature of $1730 \mathrm{~K}$, the value of $\mathrm{t}_{\mathrm{eq}}$ is $30 \mathrm{~s}$. For cladding at a temperature of $1435 \mathrm{~K}$, the value of $t_{\text {eq }}$ is $120 \mathrm{~s}$. For temperatures between the temperature values shown in Table 2, the value of $\mathrm{t}_{\mathrm{eq}}$ will be found by linear interpolation. 
Table 2. Period of hydrogen uptake (parameter $\mathrm{t}_{\mathrm{eq}}$ ) as a function of temperature.

\begin{tabular}{|c|c|}
\hline $\begin{array}{c}\text { Cladding } \\
\text { temperature } \\
(\mathrm{K})\end{array}$ & $\begin{array}{c}\mathrm{t}_{\mathrm{eq}} \\
(\mathrm{s})\end{array}$ \\
\hline \hline$<1240$ & 300 \\
\hline 1240 & 300 \\
\hline 1340 & 200 \\
\hline 1435 & 120 \\
\hline 1540 & 60 \\
\hline 1640 & 40 \\
\hline 1730 & 30 \\
\hline 1730 & 30 \\
\hline
\end{tabular}

The uptake of hydrogen is an exothermic reaction that accelerates the heatup of the fuel rod. The heatup due to hydrogen uptake is calculated by the equation:

$$
\dot{Q}_{H}=-2 \pi r_{o} \xi_{o} \rho_{M} \Delta H_{H S I}\left(C_{H 2}-C_{H 1}\right) / \Delta t
$$

where

$$
\begin{array}{lll}
\dot{Q}_{H} & = & \text { rate of heat generation at an axial node due to uptake of hydrogen }(\mathrm{W} / \mathrm{m}), \\
r_{o} & = & \text { radius of external surface of cladding }(\mathrm{m}), \\
\Delta z & = & \text { height of axial node }(\mathrm{m}), \\
\rho_{M} & = & \text { molar density of } \mathrm{Zr} \text { in zircaloy }\left(\mathrm{k}_{\mathrm{g}} \cdot \mathrm{mol} / \mathrm{m}^{3}\right), \\
\xi_{o} & = & \text { as-fabricated thickness of cladding }(\mathrm{m}), \\
\Delta H_{H S I} & = & \text { enthalpy of solution in SI units }\left(\mathrm{J} / \mathrm{k}_{\mathrm{g}} \cdot \mathrm{mole}\right), \\
C_{H 2} & = & \mathrm{H} / \mathrm{Zr} \text { ratio in cladding at end of time step, } \\
C_{H 1} & = & \mathrm{H} / \mathrm{Zr} \text { ratio in cladding at start of time step, } \\
\Delta t & = & \text { time step (s). }
\end{array}
$$

The enthalpy of solution, $\Delta H_{H}$, has a value of $-13.1 \mathrm{kcal} / \mathrm{mol}^{3}$ for Zircaloy with a $\mathrm{O} / \mathrm{Zr}$ ratio of 0.2 . Converting the units of the enthalpy of solution to SI units, the result is:

$\Delta H_{H S I}=-3.129 \times 10^{6}$ 
where

$$
\Delta H_{H S I}=\quad \text { enthalpy of solution }\left(\mathrm{J} / k_{g}-\mathrm{mol}\right) \text {. }
$$

The enthalpy of solution varies slightly with variation in the $\mathrm{O} / \mathrm{Zr}$ ratio of the cladding, but may vary significantly with $(\mathrm{H} / \mathrm{Zr})$ ratio $^{16}$. Since the enthalpy of solution as a function of $(\mathrm{H} / \mathrm{Zr})$ ratio is not available for the present report, $\Delta H_{H S I}$ is assumed to not be a function of $(\mathrm{H} / \mathrm{Zr})$ ratio. The test results of the model will be examined to evaluate whether this assumption is justified.

The rate of heat generation due to hydrogen uptake is calculated to not be as significant as implied by Olander. ${ }^{3}$ Given the typical severe accident conditions as defined in Table 3, Equations (41) and (45) calculate that the average rate of heat generation due to hydrogen uptake through the period of hydrogen uptake is only $36 \mathrm{~W} / \mathrm{m}$. This rate of heatup is small compared to the rate of heat generation due to oxidation under these same conditions, which is calculated to be about $400 \mathrm{~W} / \mathrm{m}$.

Table 3. Conditions for example calculation of rate of heat generation due to hydrogen uptake

\begin{tabular}{|c|c|c|}
\hline Variable & Units & Value \\
\hline \hline$P_{H 2}$ & $M P a$ & 3.0 \\
\hline$T$ & $K$ & 2000 \\
\hline$r_{O}$ & $m$ & $4.8 \times 10^{-3}$ \\
\hline$\xi_{O}$ & $m$ & $0.6 \times 10^{-3}$ \\
\hline$\rho_{m}$ & $\mathrm{~kg}-\mathrm{mol} / \mathrm{m}^{3}$ & 70.5 \\
\hline$\Delta H_{H S I}$ & $\mathrm{~J} / \mathrm{kg}-\mathrm{mol}$ & $-3.129 \times 10^{6}$ \\
\hline$C_{H 2}-C_{H 1}$ & $H / \mathrm{Zr} \mathrm{ratio}$ & 0.27 \\
\hline$\Delta t$ & $s$ & 50. \\
\hline
\end{tabular}

After the hydrogen concentration has reached the solubility limit (equilibrium level), the further heatup of the cladding results in a reduction in solubility and thus a release of hydrogen. The desorption of hydrogen is endothermic and results in the cladding functioning as a heat sink.

\section{Cladding Embrittlement and Hydrogen Release}

Hydrogen may be stored in the cladding due to hydrogen uptake during a period of steam-starved oxidation $^{6,7}$ and then be released during a quenching period when the cladding may crack due to thermal stresses in cladding embrittled by a combination of oxygen and hydrogen uptake. ${ }^{7,8}$ The embrittlement of the cladding decreases its ductility to the point that the stresses induced by a temperature gradient during quenching may result in cracking of the cladding. So the existing model in SCDAP/RELAP5 for determining when the cladding cracks needs to be extended to account for the effect of hydrogen uptake on the structural integrity of the cladding during a reflood of the reactor core. The model will be applied to determine the time at which the cladding at any location may crack to the extent that hydrogen absorbed in the metallic phase of the cladding is released and oxygen from the coolant may contact the inner surface of the cladding. 
A model accounting for the effect of hydrogen uptake on structural integrity will be presented that is based on the results of experiments that involved the reflood of hot fuel rods. Neither a theoretical model or a broadly-based empirical model appropriate for SCDAP/RELAP5 were found in the literature. The phase diagram for the $\mathrm{Zr}-\mathrm{H}$ system as shown in Figure 5 provides an indication of the ranges of temperature and

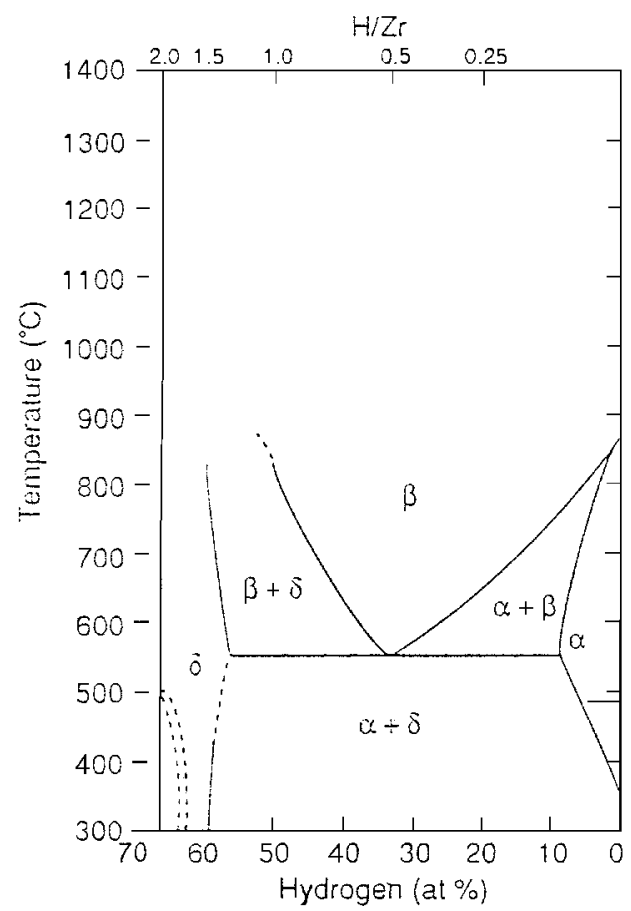

Figure 5. The zirconium-hydrogen phase diagram.

hydrogen concentration in which the cladding may be embrittled. The key feature of this diagram relative to embrittlement is the eutectoid reaction at about $550^{\circ} \mathrm{C}(823 \mathrm{~K})$ which upon cooldown produces the brittle hydride phase in equilibrium with zirconium. The Appendix $\mathrm{K}^{9}$ embrittlement criteria defines the cladding to be embrittled when it is more than $17 \%$ oxidized. This criteria is considered to have enough conservatism that the additional embrittlement due to hydrogen uptake does not need to be taken into account. ${ }^{8}$ Its conservatism does not make it appropriate for SCDAP/RELAP5. The Chung and Kassner embrittlement model ${ }^{10}$ defines cladding to be embrittled when the thickness of the beta phase of the cladding is less than $0.1 \mathrm{~mm}$ and the concentration of hydrogen in the metal phase is less than 20 at.\% (2200 ppm). Recent experimental results indicate that this model may not account fully for the effect of hydrogen concentration on embrittlement and that it may not be applicable for rapid cooling in a steam environment such as may occur above a quench front. ${ }^{7}$ So an extension of existing models for embrittlement to account for hydrogen uptake will be developed as follows. First, experimental results will be compiled that present a picture of the effect of the thickness of the cladding oxide layer and hydrogen concentration on cladding integrity during reflood. Then, an extension will be made to the Chung and Kassner model to account for these experimental results.

Experimental results applicable for evaluating the structural integrity of fuel rods during quenching are available from several sources. Results from the QUENCH program at the Forschungszentrum in Karlsruhe, Germany for fuel rods quenched from maximum temperatures of $1473 \mathrm{~K}$ and $1673 \mathrm{~K}$ are shown in Figure 6 and Figure 7, respectively. ${ }^{7}$ The crack density data shown in these figures apply to the rapid cooling in steam 


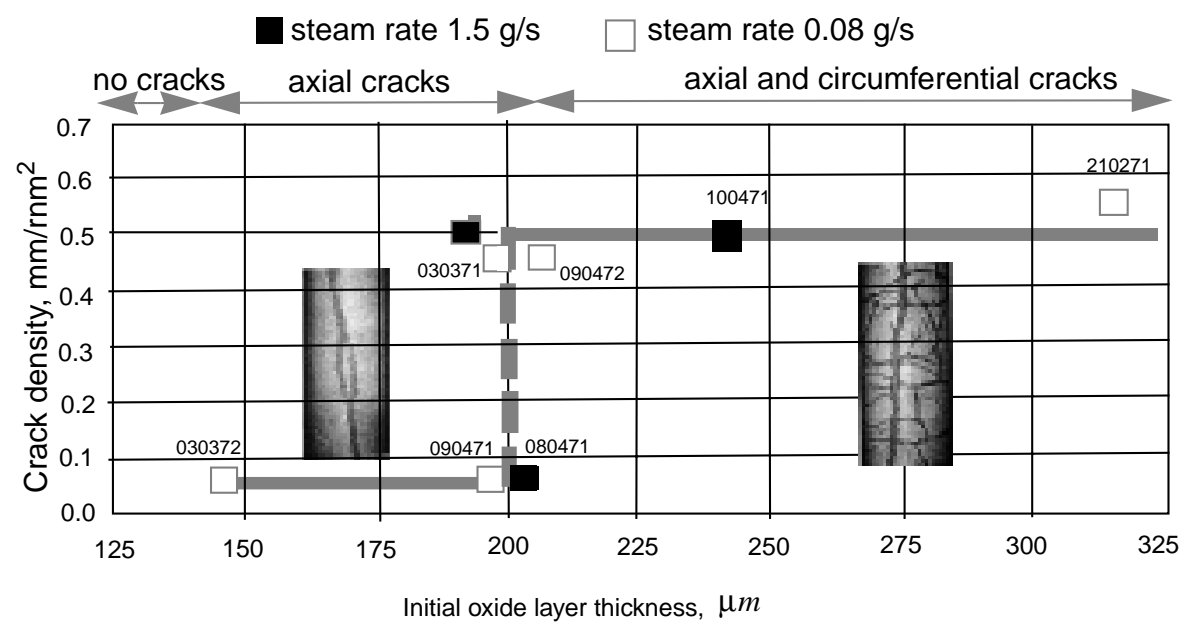

Figure 6. Crack formation in preoxidized Zircaloy during rapid cooldown from $1200^{\circ} \mathrm{C}$ by steam.

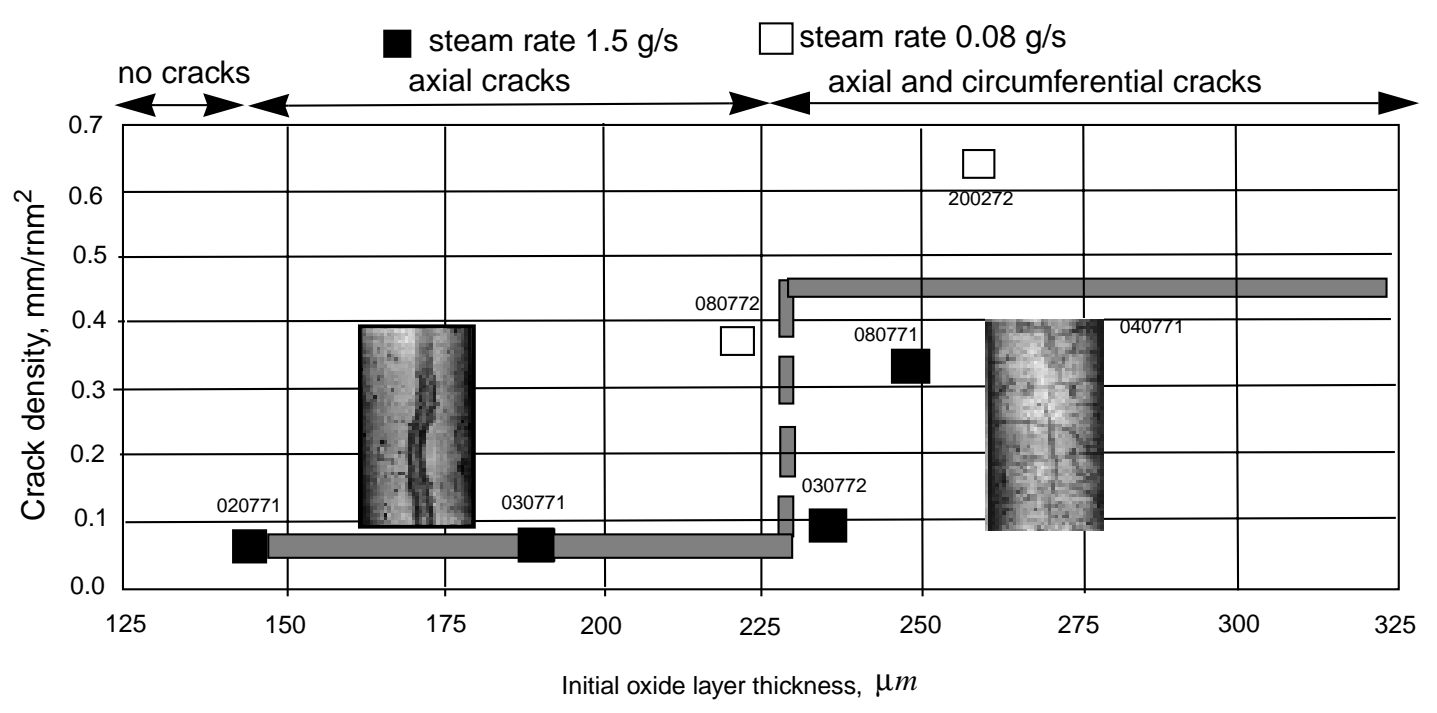

Figure 7. Crack formation in preoxidized Zircaloy during rapid cooldown from $1400^{\circ} \mathrm{C}$ by steam.

$(\sim 50 \mathrm{~K} / \mathrm{s})$ of fuel rods that were heated in a steam environment to temperatures in the range of $1473 \mathrm{~K}$ to $1673 \mathrm{~K}$. As shown in these figures, oxide layer thicknesses less than $0.15 \mathrm{~mm}$ did not result in cracking of the cladding. Oxide layer thicknesses in the range $0.15 \mathrm{~mm}$ to $0.225 \mathrm{~mm}$ resulted in axial cracks in the cladding that penetrated through the wall of the cladding. Oxide layer thicknesses greater than $0.225 \mathrm{~mm}$ resulted in both axial and circumferential cracks in the cladding. In general, axial and circumferential cracks did not occur unless the oxide layer before quenching was greater than $0.2 \mathrm{~mm}$. This threshold thickness increases somewhat with increasing temperature prior to quenching. As shown in Figure 6, the threshold thickness was $0.2 \mathrm{~mm}$ for a cladding temperature of $1473 \mathrm{~K}$ prior to quenching, and was 0.225 
$\mathrm{mm}$ for a cladding temperature of $1673 \mathrm{~K}$ (Figure 7). Experiments performed at Argonne National Laboratory on the quenching of hot and partially oxidized fuel rods indicated that cracking of the cladding did not occur provided that the thickness of the beta phase of the cladding was greater than $0.1 \mathrm{~mm}$ and the hydrogen concentration was less than 20 at. $\%{ }^{10}$ These experiments quenched the fuel rods with water and involved cooling rates of order of $100 \mathrm{~K} / \mathrm{s}$. Experiments performed in the Power Burst Facility at the Idaho National Engineering and Environmental Laboratory on the quenching of hot and partially oxidized fuel rods indicated that cracking of the cladding may occur during quenching when the hydrogen concentration in the cladding exceeds 10 at.\%. ${ }^{11}$ These experiments also quenched the fuel rods with water and involved cooling rates of order of $100 \mathrm{~K} / \mathrm{s}$. Experiments performed at the Japan Atomic Energy Research Institute in Japan on the quenching of cladding under reflood conditions for large break Loss of Coolant Accidents indicate that hydrogen concentrations in excess of 20 at.\% may contribute to the embrittlement of the cladding. ${ }^{8}$

The experimental results can be used as a basis for extending the Chung and Kassner embrittlement model to account for hydrogen concentration and thickness of oxide layer. The extended embrittlement model is defined in Table 4. Blank column entries in a row indicate that embrittlement for that row is not a function of those column entries. As shown in Table 4, cladding with an oxide layer greater than $0.2 \mathrm{~mm}$ in

Table 4. Model for determining whether cladding is embrittled

\begin{tabular}{|c|c|c|c|}
\hline $\begin{array}{c}\text { Beta phase } \\
\text { thickness }\end{array}$ & $\begin{array}{c}\text { Oxide layer } \\
\text { thickness }\end{array}$ & $\begin{array}{c}\text { Hydrogen } \\
\text { concentration }\end{array}$ & Embrittled? \\
\hline$(\mathrm{mm})$ & $(\mathrm{mm})$ & at.\% & yes/no \\
\hline \hline$>0.1$ & $<0.2$ & $<10$ & no \\
\hline$<0.1$ & - & - & yes \\
\hline- & $>0.2$ & - & yes \\
\hline- & - & $>10$ & yes \\
\hline
\end{tabular}

thickness is defined to be embrittled independent of the values for beta phase thickness and hydrogen concentration. Cladding with a hydrogen concentration greater than 10 at.\% is defined to be embrittled independent of the value of beta phase thickness or oxide layer thickness.

Embrittled cladding will be assumed to crack when it is cooled to the temperature of $820 \mathrm{~K}$ at a rate greater than a user-defined threshold rate of cooling for inducement of cracking. The user-defined threshold will be assigned a default value of $50 \mathrm{~K} / \mathrm{s}$. This default value is based upon the cooling rates used in experiments that showed cracking of the cladding during quenching. The temperature of $820 \mathrm{~K}$ is based upon the $\mathrm{Zr}-\mathrm{H}$ phase diagram and experimental results. As shown previously in Figure 5, a phase change occurs in the $\mathrm{Zr}-\mathrm{H}$ system for a broad range of hydrogen concentrations at a temperature of about $820 \mathrm{~K}$. As shown in Figure 8 for an experiment performed for the QUENCH program at FZK, a significant release in absorbed hydrogen was observed to occur as cladding cooled to a temperature less than $800 \mathrm{~K}$ $\left(527^{\circ} \mathrm{C}\right) .^{7}$ 


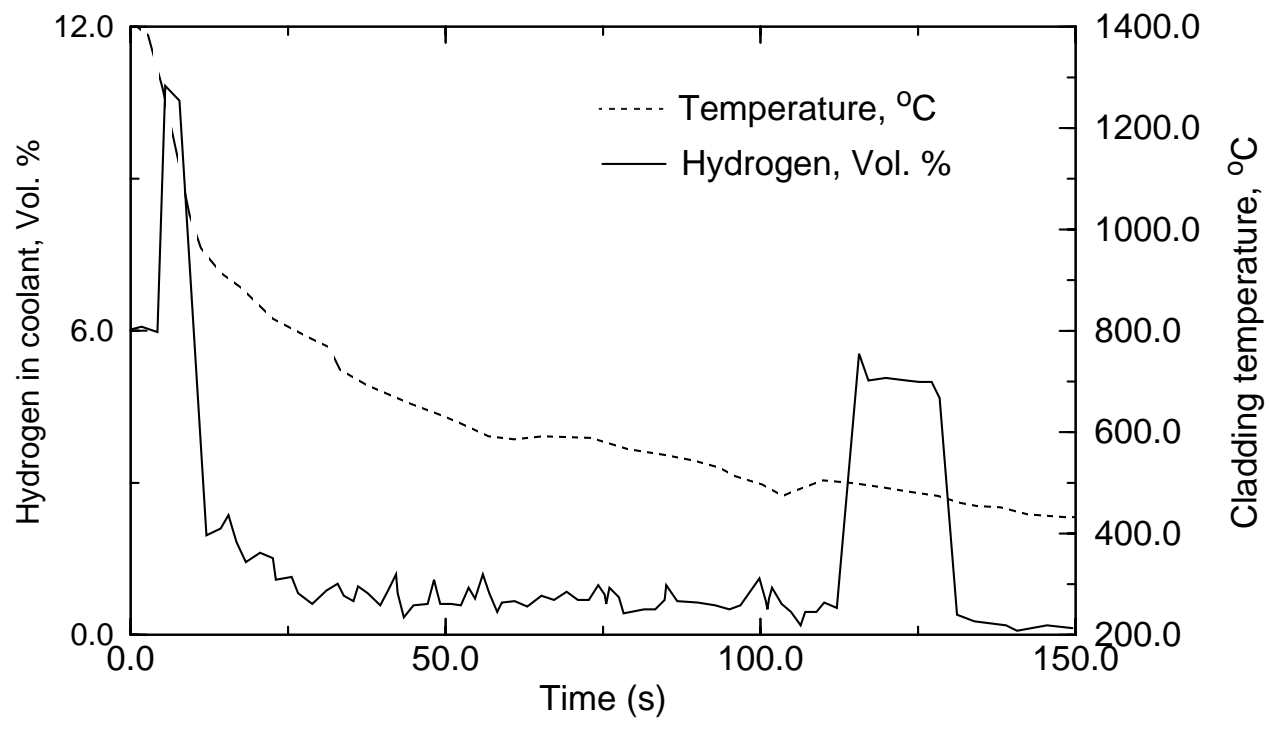

Figure 8. Temperature history and corresponding hydrogen release.

Ideally, a calculation would be performed of the stresses and strains in the metallic and oxidic layers of the cladding due to the large radial temperature gradients which occur during the quenching of hot fuel rods. The calculated stresses and strains would be compared with a model that defined the stresses and strains for cracking of the cladding as a function of temperature and concentrations of hydrogen and oxygen. The application of these models would account for the reduction in ductility of the cladding that occurs in certain phases of the $\mathrm{Zr}-\mathrm{O}$ and $\mathrm{Zr}-\mathrm{H}$ phase diagrams. But models to calculate these stresses and strains in the cladding require structural material properties as a function of concentrations of hydrogen and oxygen that are not available for high temperatures. So a determination of the times and localities at which the cladding cracks can only be based upon experimental results.

As shown previously in Figure 8, the cracking of the cladding during quenching results in release of the hydrogen absorbed in the metallic phase of the cladding. This release of hydrogen will be modeled by applying the same simplified approach used in modeling hydrogen uptake after complete dissolution of the oxide layer. This simplified approach was presented in Section 3 and is justified by experimental results that show hydrogen is quickly released following a change in boundary conditions that allows the release of hydrogen. ${ }^{4}$ After cracking of the oxide layer occurs, the oxide layer will be assumed to apply no resistance to the diffusion of hydrogen from the metallic layer to the bulk coolant. The rate of hydrogen release will be based on experimental results shown in Figure 8. This figure shows that hydrogen was released at about a constant rate during a $20 \mathrm{~s}$ period after the cladding cooled to a temperature less than $800 \mathrm{~K}$. There is no obvious physical reason for hydrogen release at a constant rate, but the only available experimental results indicate that this is the case.

Thus, the reduction in fractional hydrogen concentration in the cladding as a function of time will be calculated by the equation

$$
C_{H}=C_{H S}\left(1-\left[\frac{\left(t-t_{c r k}\right)}{t_{r e q}}\right]\right)
$$


where

$$
\begin{array}{lll}
\mathrm{C}_{\mathrm{H}} & = & \text { fractional hydrogen concentration at time } \mathrm{t}(\mathrm{H} / \mathrm{Zr} \text { ratio }), \\
\mathrm{C}_{\mathrm{HS}} & = & \begin{array}{l}
\text { fractional hydrogen concentration just before start of cracking of cladding }(\mathrm{H} / \mathrm{Zr} \\
\text { ratio }),
\end{array} \\
\mathrm{t} & = & \text { time }(\mathrm{s}), \\
\mathrm{t}_{\mathrm{crk}} & = & \text { time at which cladding cracked }(\mathrm{s}), \\
\mathrm{t}_{\mathrm{req}} & = & \text { experimentally measured release time }(\mathrm{s}) .
\end{array}
$$

In order to accommodate experimental results that may be available in the future, the variable $t_{\text {req }}$ will be user-defined. Based upon the experimental results shown in Figure 8, the variable $t_{\text {req }}$ is assigned a default value of $20 \mathrm{~s}$.

The release of hydrogen to the bulk coolant during a time step is given by the equation

$$
w_{h r c i}=2 \pi r_{o} \Delta z \xi\left(C_{H 1}-C_{H 2}\right) \rho_{m}
$$

where

$$
\begin{array}{lll}
\mathrm{w}_{\mathrm{hrci}} & = & \begin{array}{l}
\mathrm{kg}-\mathrm{mol} \text { of } \mathrm{H}_{2} \text { released to bulk coolant due to cracking of cladding at axial node } \\
\mathrm{i},
\end{array} \\
\mathrm{r}_{\mathrm{O}} & = & \text { outer node of cladding at axial node } \mathrm{i}(\mathrm{m}), \\
\Delta z & = & \text { height of axial node } \mathrm{i}(\mathrm{m}), \\
\xi & = & \text { thickness of metallic phase of cladding at axial node } \mathrm{i}(\mathrm{m}), \\
\mathrm{C}_{\mathrm{H} 1} & = & \text { fractional hydrogen concentration at start of time step }(\mathrm{H} / \mathrm{Zr} \text { ratio }), \\
\mathrm{C}_{\mathrm{H} 2} & = & \text { fractional hydrogen concentration at end of time step }(\mathrm{H} / \mathrm{Zr} \text { ratio }), \\
\rho_{m} & = & \text { molar density of } \mathrm{Zr} \text { in Zircaloy }\left(70.5 \mathrm{~kg}-\mathrm{mol} / \mathrm{m}^{3}\right) .
\end{array}
$$

Hydrogen release is also caused by the oxidation of cladding. ${ }^{4}$ This mechanism for release occurs because the hydrogen solubility in $\mathrm{ZrO}_{2}$ is very small. In this sense, hydrogen behaves similar to the fission product tellurium, which is strongly bound by $\mathrm{Zr}$ but not by $\mathrm{ZrO}_{2}{ }^{4}$. With respect to tellurium, oxidation "squeezes" the tellurium into the ever diminishing metallic part of the cladding and then a puff of tellurium release occurs as the last small part of the metallic layer is oxidized. Since the concentration of tellurium in the cladding is estimated to be much less than the concentration of hydrogen, oxidation of the cladding will not be considered to squeeze the hydrogen into the ever diminishing metallic layer. Instead, an immediate release of the hydrogen in the portion of the cladding oxidized during a time step will be assumed. The oxidation driven release of hydrogen will be calculated by the equation

$w_{\text {hroi }}=2 \pi r_{o} \Delta z\left(\xi_{1}-\xi_{2}\right) C_{H} \rho_{m}$ 
where

$$
\begin{aligned}
& \mathrm{w}_{\text {hroi }}=\mathrm{kg} \text {-mol of hydrogen released to bulk coolant at axial node } \mathrm{i}, \\
& \mathrm{r}_{\mathrm{o}} \quad=\quad \text { outer radius of cladding at axial node } \mathrm{i}(\mathrm{m}) \text {, } \\
& \Delta z \quad=\quad \text { height of axial node } \mathrm{i}(\mathrm{m}), \\
& \xi_{1}=\quad \text { thickness of metallic layer of cladding at axial node } \mathrm{i} \text { at start of time step }(\mathrm{m}) \text {, } \\
& \xi_{2}=\text { thickness of metallic layer of cladding at axial node } \mathrm{i} \text { at end of time } \mathrm{s} \text {, } \\
& \mathrm{C}_{\mathrm{H}}=\text { fractional hydrogen concentration at start of time step at } \\
& \text { axial node i ( } \mathrm{H} / \mathrm{Zr} \text { ratio), } \\
& \rho_{m} \quad=\quad \text { molar density of Zr in Zircaloy }\left(70.5 \mathrm{~kg}-\mathrm{mol} / \mathrm{m}^{3}\right) \text {. }
\end{aligned}
$$

\section{Implementation of Models}

The modeling of oxygen and hydrogen uptake and its consequences requires the implementation of several different models into different parts of SCDAP/RELAP5. This section defines where in the SCDAP/RELAP5 framework the different models are to be linked.

A new subroutine named OXIDIF was programmed to calculate the uptake of oxygen and hydrogen using the integral diffusion method. This subroutine is connected to the existing SCDAP/RELAP5 programming framework as shown in Figure 9. Subroutine FUELAN is the driver subroutine for

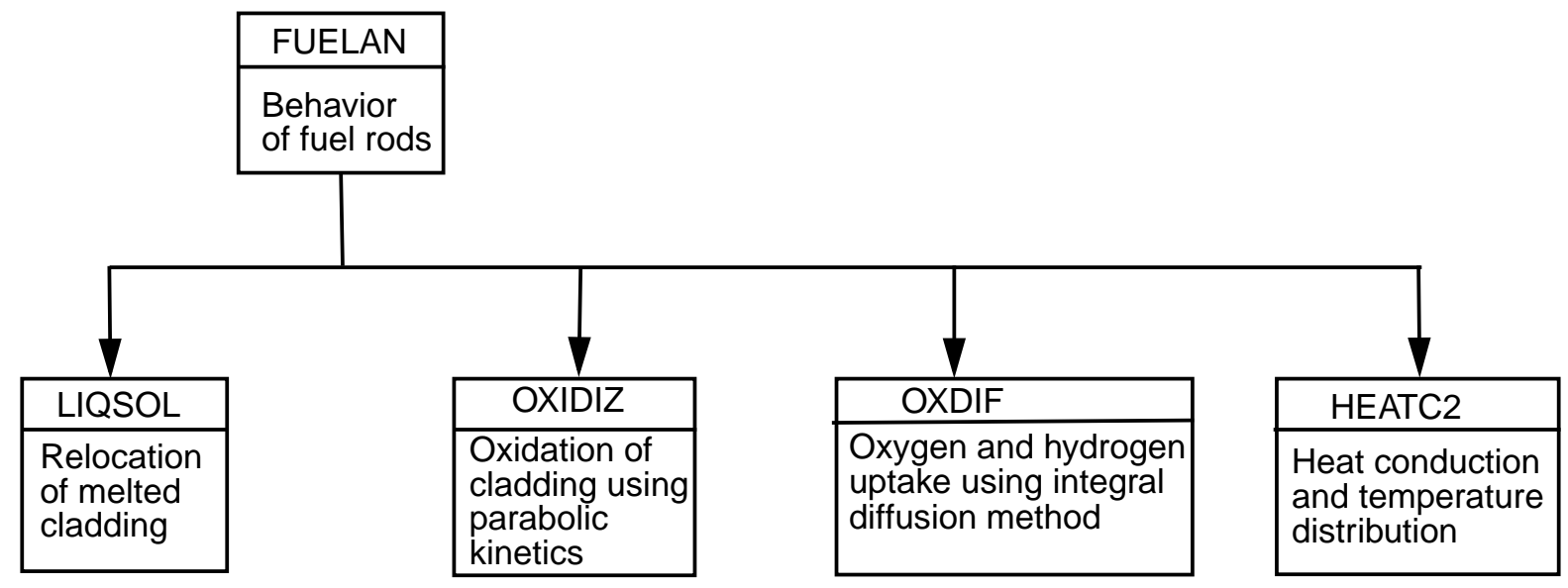

Figure 9. Implementation of oxygen and hydrogen uptake models into frame work of SCDAP/RELAP5 programming.

calculating the behavior of fuel rods. It calls subroutines such as LIQSOL that calculates the meltdown of fuel rods and OXIDIF that calculates the oxidation of fuel rod cladding. Two subroutines were programmed for MATPRO to calculate the oxygen transport material properties of the cladding. A subroutine named DIFZOX was programmed to calculate the diffusion coefficient of oxygen in the oxide 
layer as a function of temperature. A subroutine named DIFZRM was programmed to calculate the diffusion coefficient of oxygen in the cladding metallic layer as a function of temperature.

\section{Assessment of Early-Phase Damage Progression Models}

This section presents the assessment of the oxygen and hydrogen uptake models described in this report. The assessment was performed using the MOD3.3 models for the configuration and integrity of hot and partially oxidized cladding. ${ }^{19}$ Thus, the assessment evaluates the major extensions made to MOD3.3 for the modeling of early-phase damage progression. The MOD3.3 models were assessed using the results of four integral severe fuel damage tests: (1) PBF SFD 1-1 ${ }^{20}$, (2) PBF SFD 1-4 ${ }^{12}$, (3) NRU FLHT- $5^{21}$, and (4) FzK CORA-7 ${ }^{13}$. A summary of these four experiments is given in Table 5. Each of these experiments obtained measurements of the total hydrogen production and transient fuel rod temperatures at several different elevations. Also, post-test examinations were performed for these test bundles to obtain information on axial distribution in cladding oxidation and blockage. Each of these experiments was analyzed using ten axial nodes and a component grouping for each ring of fuel rods in the test bundle. A more complete description of these four experiments and the nodalization of the test bundle is described in Reference 15.

Table 5. Summary of the four experiments used for assessment

\begin{tabular}{|c|c|}
\hline Experiment & Description \\
\hline PBF SFD 1-1 & $\begin{array}{c}6 \times 6 \text { bundle of rods with nuclear heating, length of } 0.91 \mathrm{~m} \text {, trace of burnup, no } \\
\text { control rods, cooled by boilaway of water at pressure of } 6.8 \mathrm{MPa} \text {, slow } \\
\text { cooldown }\end{array}$ \\
\hline PBF SFD 1-4 & $\begin{array}{c}6 x 6 \text { bundle of rods with nuclear heating, length of } 1.0 \mathrm{~m}, 2 \text { fuel rods with bur- } \\
\text { nup of } 36 \mathrm{MWd} / \mathrm{kg} U \text {, others with trace of burnup, } 4 \mathrm{Ag} \text {-In-Cd control rods, } \\
\text { cooled by mixture of steam and Ar at pressure of } 6.8 \mathrm{MPa} \text { flowing through bun- } \\
\text { dle, slow cooldown }\end{array}$ \\
\hline NRU FLHT-5 & $\begin{array}{c}4 \times 4 \text { bundle of rods with nuclear heating, length of } 3.6 \mathrm{~m}, 1 \text { rod with burnup of } \\
28 \mathrm{MWd} / \mathrm{kg} U \text { and others with trace of burnup, no control rods, cooled by boila- } \\
\text { way of water at pressure of } 1.38 \mathrm{MPa} \text {, slow cooldown }\end{array}$ \\
\hline$F_{z} K$ CORA-7 & $\begin{array}{l}\sim 7 x 7 \text { bundle of rods with electrical heating, length of } 1.0 \mathrm{~m} \text {, no burnup, } 5 \mathrm{Ag}- \\
\mathrm{In}-\mathrm{Cd} \text { control rods, cooled by mixture of Ar and steam, slow cooldown }\end{array}$ \\
\hline
\end{tabular}

The assessment of the MOD3.3 early-phase damage progression models indicates that the improvement sought for by these models is being achieved. In general, MOD3.2 calculated an overall progression of early-phase damage progression that was in good agreement with measured results. The major deficiency in MOD3.2 calculations was a tendency to overpredict the extent of oxidation in the top part of a test bundle and to underpredict the extent of oxidation in the bottom part of the test bundle. ${ }^{19}$ The assessment of MOD3.3 indicates that for the most part this deficiency has been resolved. In general, the axial distribution in the extent of cladding oxidation is in good agreement with test results. The measured and calculated axial distribution in oxidation are compared in Table 6. For the PBF SFD 1-1 test, for example, the measured extent of cladding oxidation at the $0.75 \mathrm{~m}$ elevation was 0.11 , while the calculated extent of oxidation was 0.46 and 0.08 for MOD3.2 and MOD3.3, respectively. The relatively better agreement of the MOD3.3 calculations is primarily due to the calculation of oxidation by the integral 
diffusion method, which accounts for the thinning of the oxide layer at locations with steam starvation. At the 0.75 m elevation, MOD3.3 calculated that the oxide layer completely dissolved into the metallic layer at the time of $2050 \mathrm{~s}$. This calculated dissolution of the oxide layer is shown in Figure 10, which is a plot as a function of time of the calculated thickness of the oxide layer at the $0.75 \mathrm{~m}$ elevation. When the cladding at this location was calculated to attain its melting temperature at the time of $2200 \mathrm{~s}$, it immediately slumped due to the absence of an oxide layer to retain it. For this test, a total of $2 \mathrm{~g}$ of hydrogen was calculated to be absorbed by the cladding at locations where the oxide layer was completely dissolved. The maximum heatup due to hydrogen uptake was calculated to be $76 \mathrm{~W} / \mathrm{m}$.

Table 6. Comparison of calculated and measured axial distribution in oxidation of fuel rod cladding

\begin{tabular}{|c|c|c|c|c|}
\hline \multirow{2}{*}{ Test } & Elevation & \multicolumn{3}{|c|}{ Fraction of cladding oxidized } \\
\cline { 2 - 5 } & $(\mathrm{m})$ & measured & MOD3.2 & MOD3.3 \\
\hline \hline PBF SFD 1-1 & 0.75 & 0.11 & 0.46 & 0.08 \\
\hline PBF SFD 1-1 & 0.25 & 1.00 & 0.13 & 0.85 \\
\hline PBF SFD 1-4 & 0.85 & 0.22 & 0.86 & 0.09 \\
\hline PBF SFD 1-4 & 0.25 & 1.00 & 0.11 & 0.91 \\
\hline FLHT-5 & 1.65 & $\sim 1.0$ & 1.0 & 1.0 \\
\hline
\end{tabular}

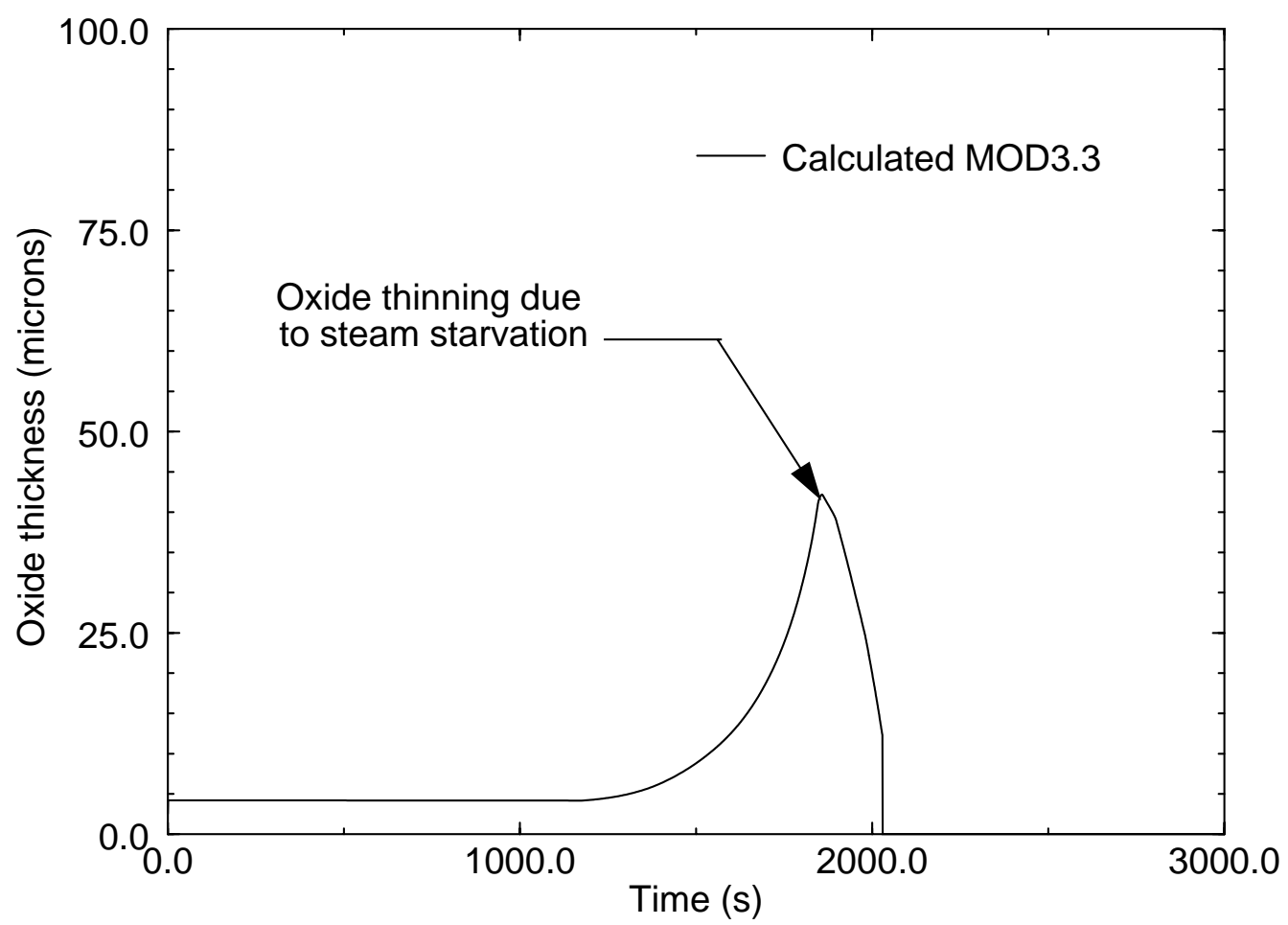

Figure 10. Calculated cladding oxide-thickness for PBF SFD 1-1 test at $0.75 \mathrm{~m}$ elevation. 
The MOD3.3 improvement in the calculation of the axial distribution in the extent of oxidation also indicates that MOD3.3 is improved in the calculation of fuel rod meltdown. The slumping of the metallic portion of the cladding at any location terminates the extent of oxidation at that location. So a good agreement of calculated and measured extent of oxidation is an indication that the calculated timing of the slumping of metallic material is in good agreement with experimental results.

The assessment also indicated that MOD3.3 calculations of hydrogen production and fuel rod heatup are in good agreement with experimental results. The comparisons of calculated and measured hydrogen production are shown in Table 7. The comparisons of calculated and measured fuel rod cladding temperatures for the PBF SFD 1-1 test at the $0.35 \mathrm{~m}$ and $0.5 \mathrm{~m}$ elevations are shown in Figure 11 and 12, respectively. The comparisons of calculated and measured fuel rod cladding temperatures for the PBF SFD $1-4$ test at the $0.39 \mathrm{~m}$ and $0.54 \mathrm{~m}$ elevations are shown in Figures 13 and 14, respectively. The comparisons of calculated and measured temperatures for the FzK CORA-7 test at the elevations of $0.55 \mathrm{~m}$ and $0.75 \mathrm{~m}$ are shown in Figures 15 and 16, respectively. The comparisons of calculated and measured temperature for the NRU FLHT-5 test at the elevations of $2.2 \mathrm{~m}$ and $2.6 \mathrm{~m}$ are shown in Figures 17 and 18, respectively. For cladding temperatures greater than $1000 \mathrm{~K}$, the heatup is driven to a considerable extent by cladding oxidation. The generally good agreement shown in Figures 11 through 18 for calculated and measured cladding temperatures indicates that the integral diffusion method is correctly calculating the rate of heatup due to oxidation. The MOD3.2 calculated temperatures are also shown in these figures. In general, the MOD3.2 and MOD3.3 are both in good agreement with experimental results, but in some cases the MOD3.3 calculations are in closer agreement with the measurements than the MOD3.2 calculations. The largest discrepancies between measured and calculated temperatures is for the NRU FLHT-5 test, which involved boil away of coolant in a full-length test bundle. The discrepancies for this test may be in part due to discrepancies in calculating the axial power distribution in the test bundle.

Table 7. Comparison of calculated and measured hydrogen production.

\begin{tabular}{|c|c|c|c|}
\hline \multirow{2}{*}{ Test } & \multicolumn{3}{|c|}{ Total hydrogen production (g) } \\
\cline { 2 - 4 } & Measured & MOD3.2 & MOD3.3 \\
\hline \hline PBF SFD 1-1 & $64 \pm 7$ & 94 & 102 \\
\hline PBF SFD 1-4 & $86 \pm 12$ & 94 & 105 \\
\hline NRU FLHT-5 & $300 \pm 30$ & 265 & 239 \\
\hline FzK CORA-7 & 114 & 79 & 117 \\
\hline
\end{tabular}

No experimental results are currently available for assessing the modeling of the timing of cladding cracking. In the absence of experiments subjecting hot embrittled cladding to varying rates of cooling centered about $50 \mathrm{~K} / \mathrm{s}$, cooled to a temperature less than $820 \mathrm{~K}$, and recording the timing of cladding cracking, no assessment of this model can be performed. 


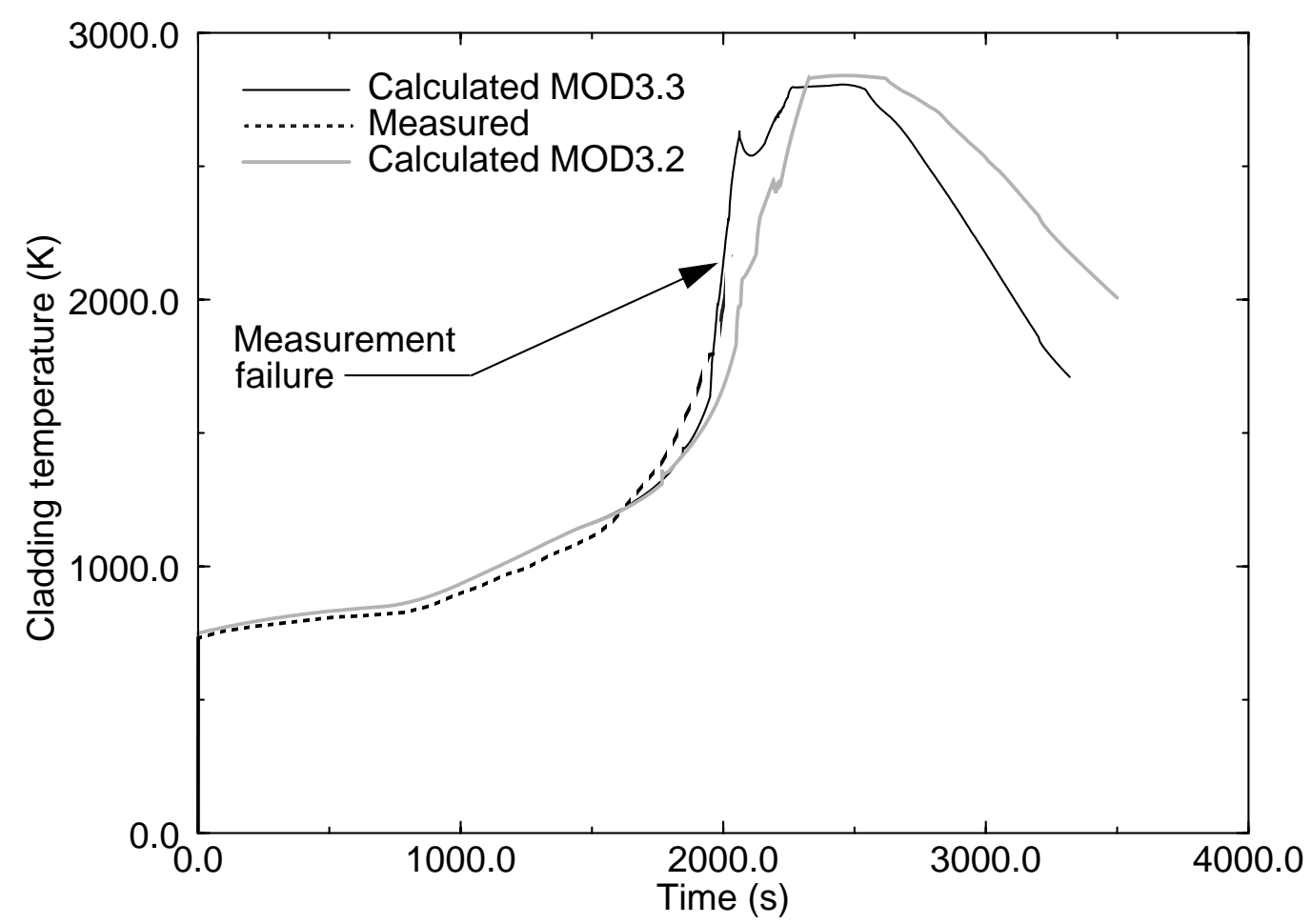

Figure 11. Comparison of calculated and measured cladding temperature for PBF SFD 1-1 test at $0.35 \mathrm{~m}$.

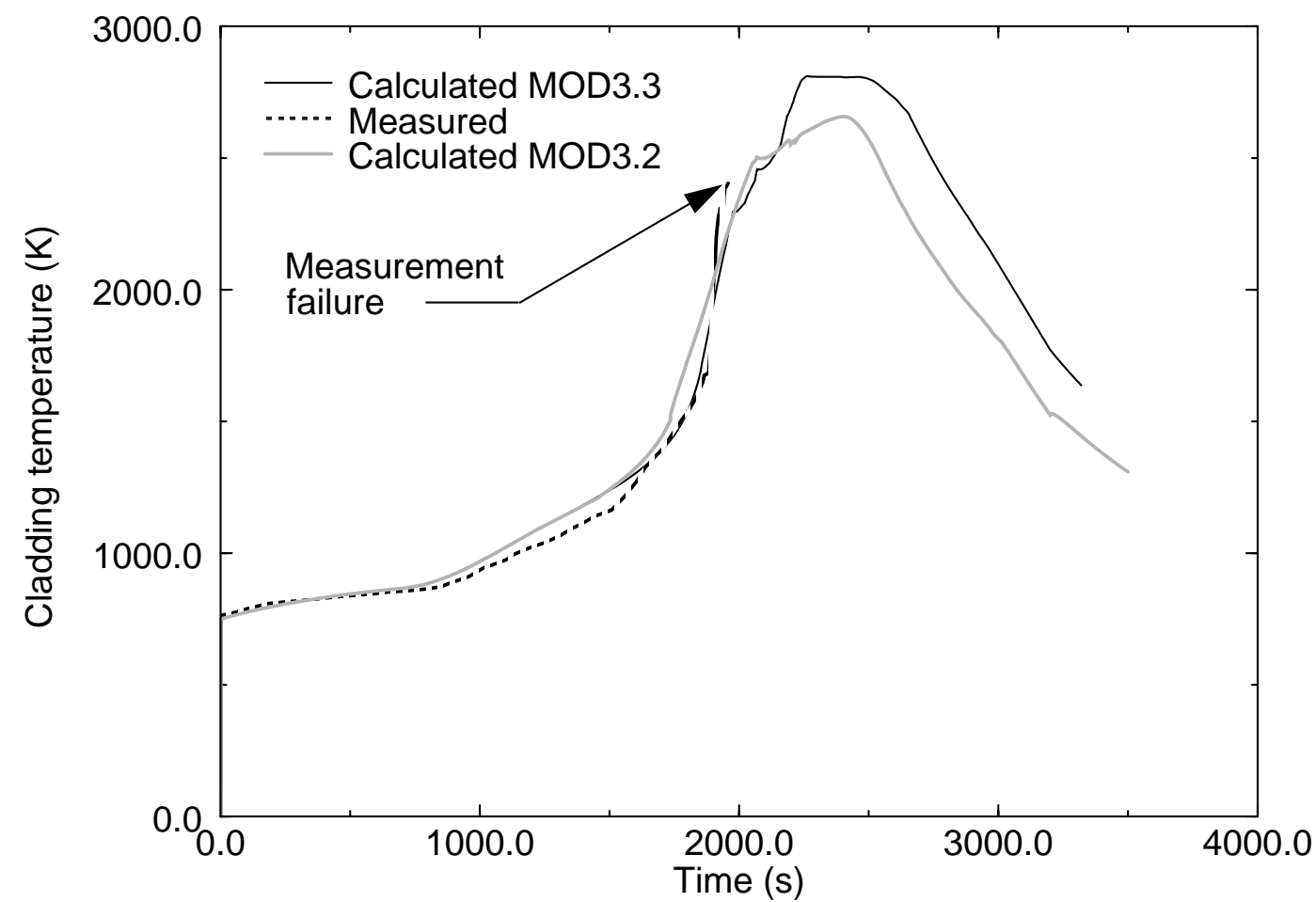

Figure 12. Comparison of calculated and measured cladding temperature for PBF SFD 1-1 test at $0.5 \mathrm{~m}$. 


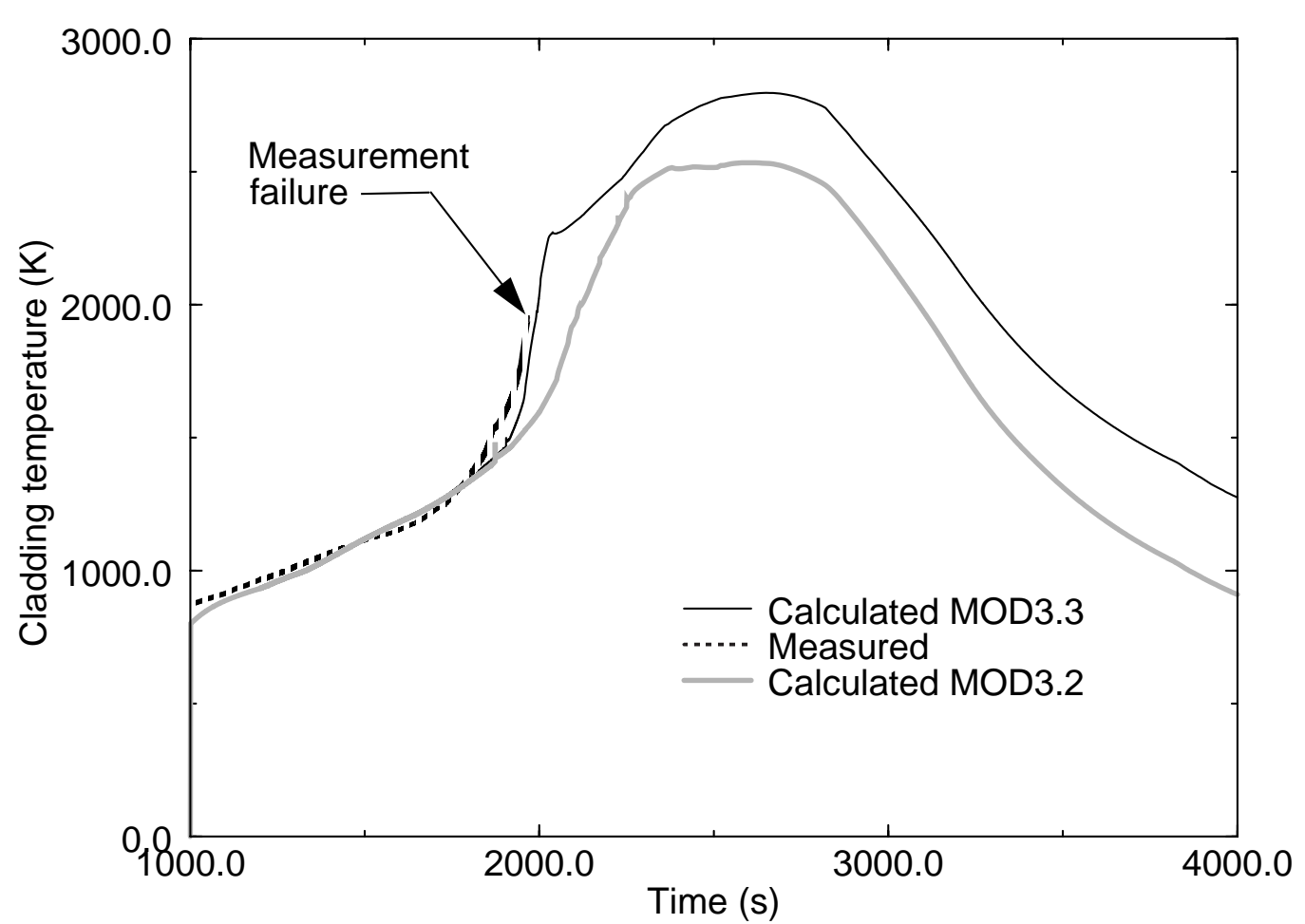

Figure 13. Comparison of calculated and measured cladding temperature for PBF SFD 1-4 test at 0.39.

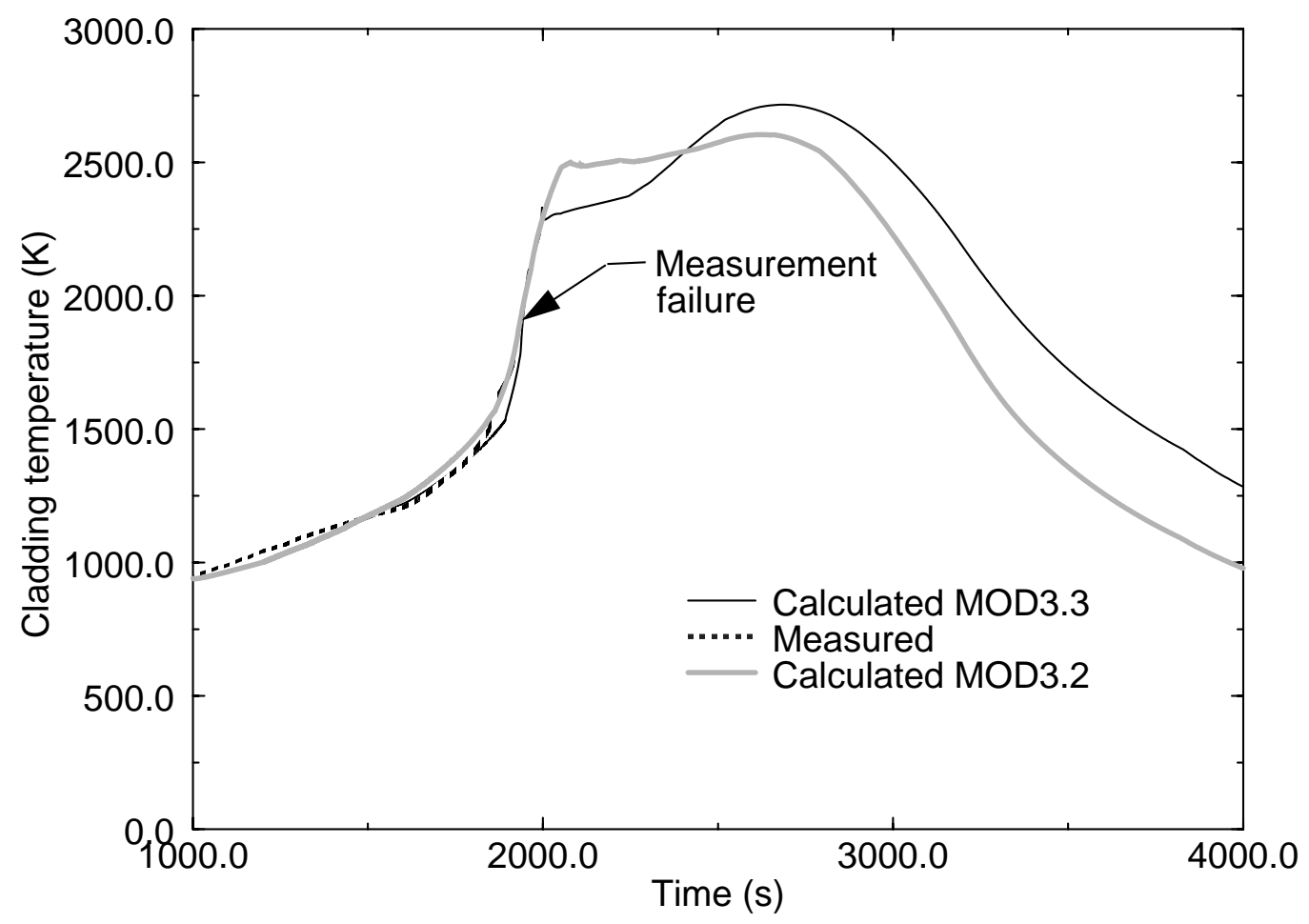

Figure 14. Comparison of calculated and measured cladding temperature for PBF SFD 1-4 test at $0.54 \mathrm{~m}$. 


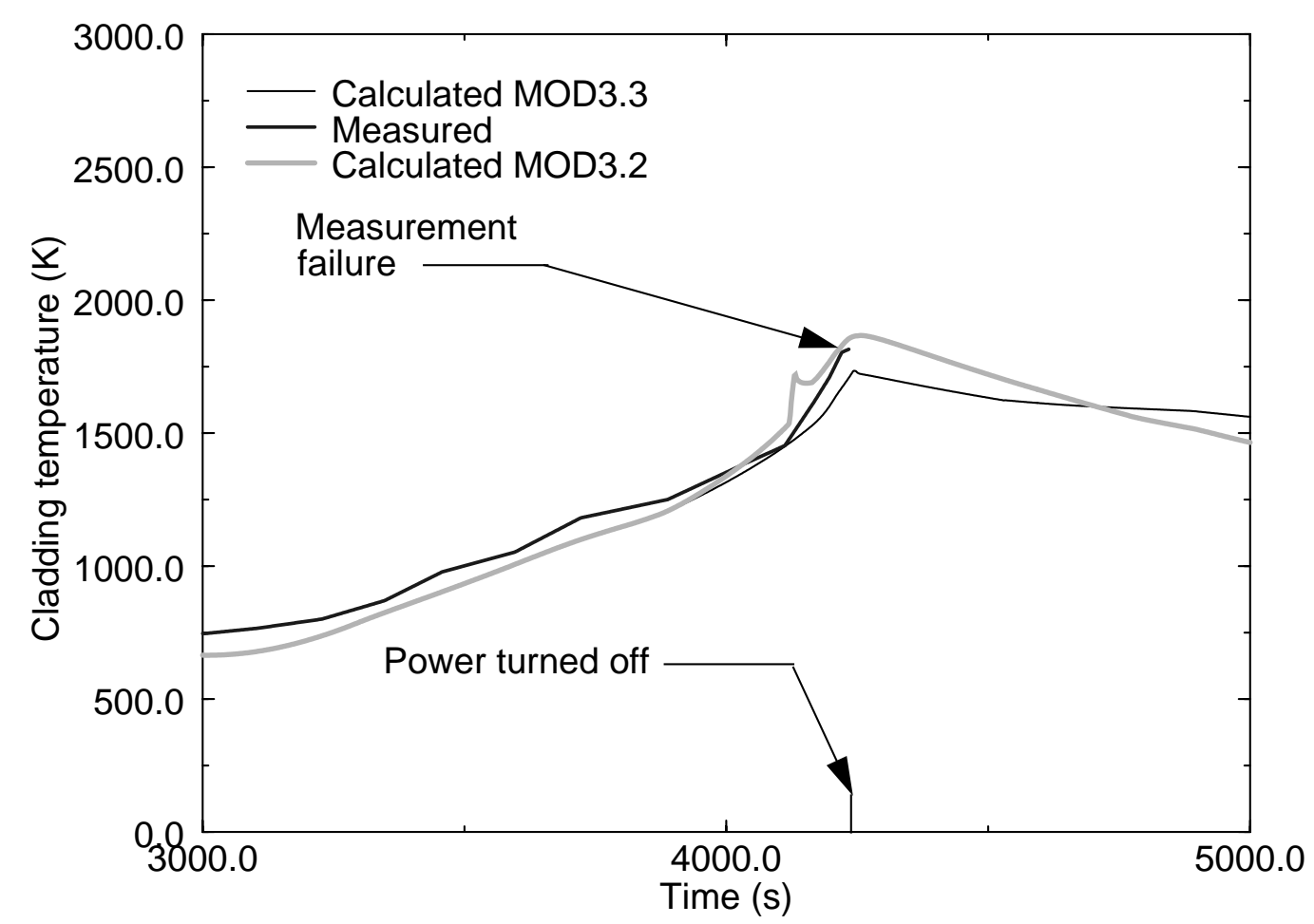

Figure 15. Comparison of calculated and measured cladding temperatures for FzK CORA-7 test at 0.55 m.

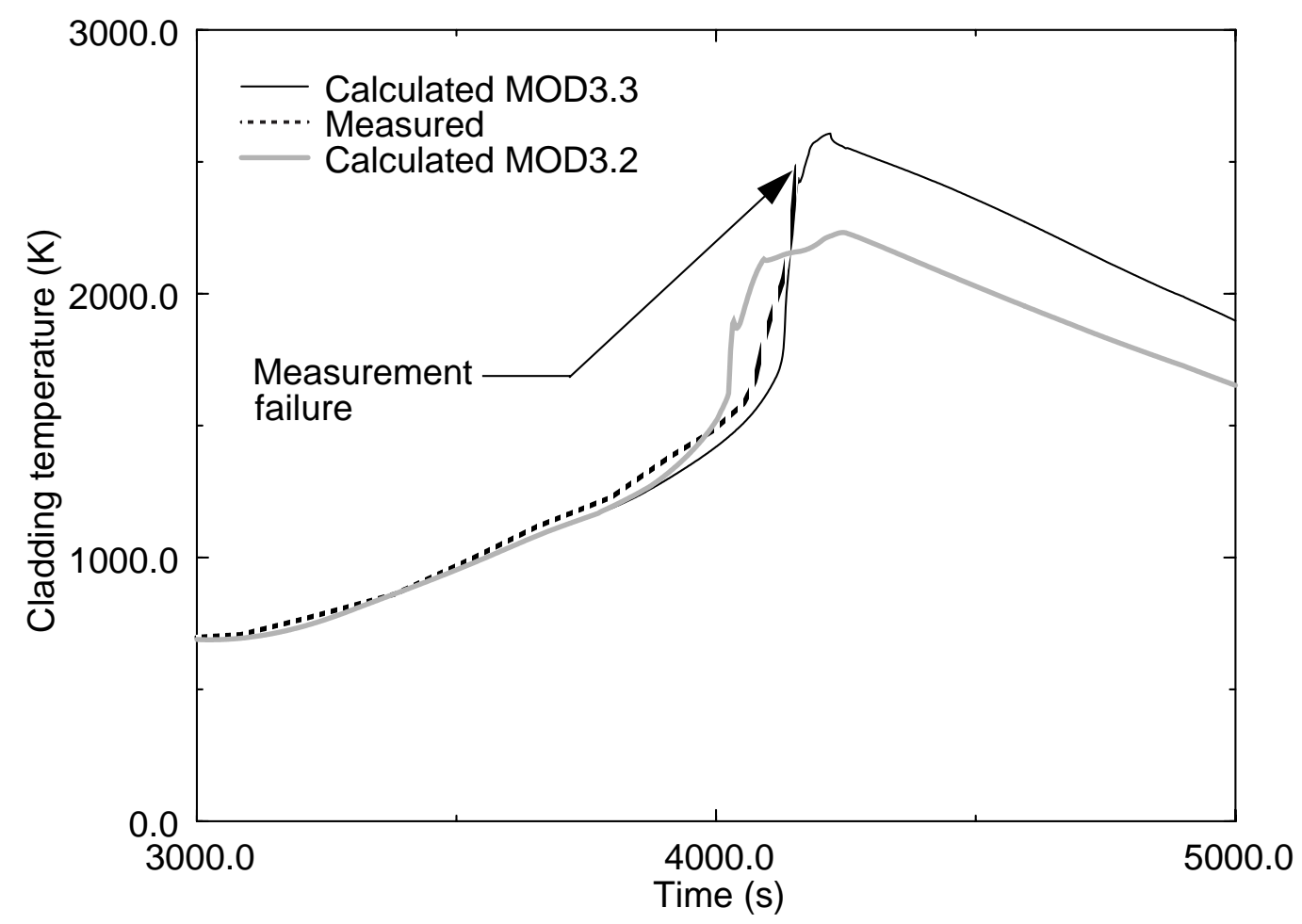

Figure 16. Comparison of calculated and measured cladding temperature for FzK CORA-7 test at $0.75 \mathrm{~m}$. 


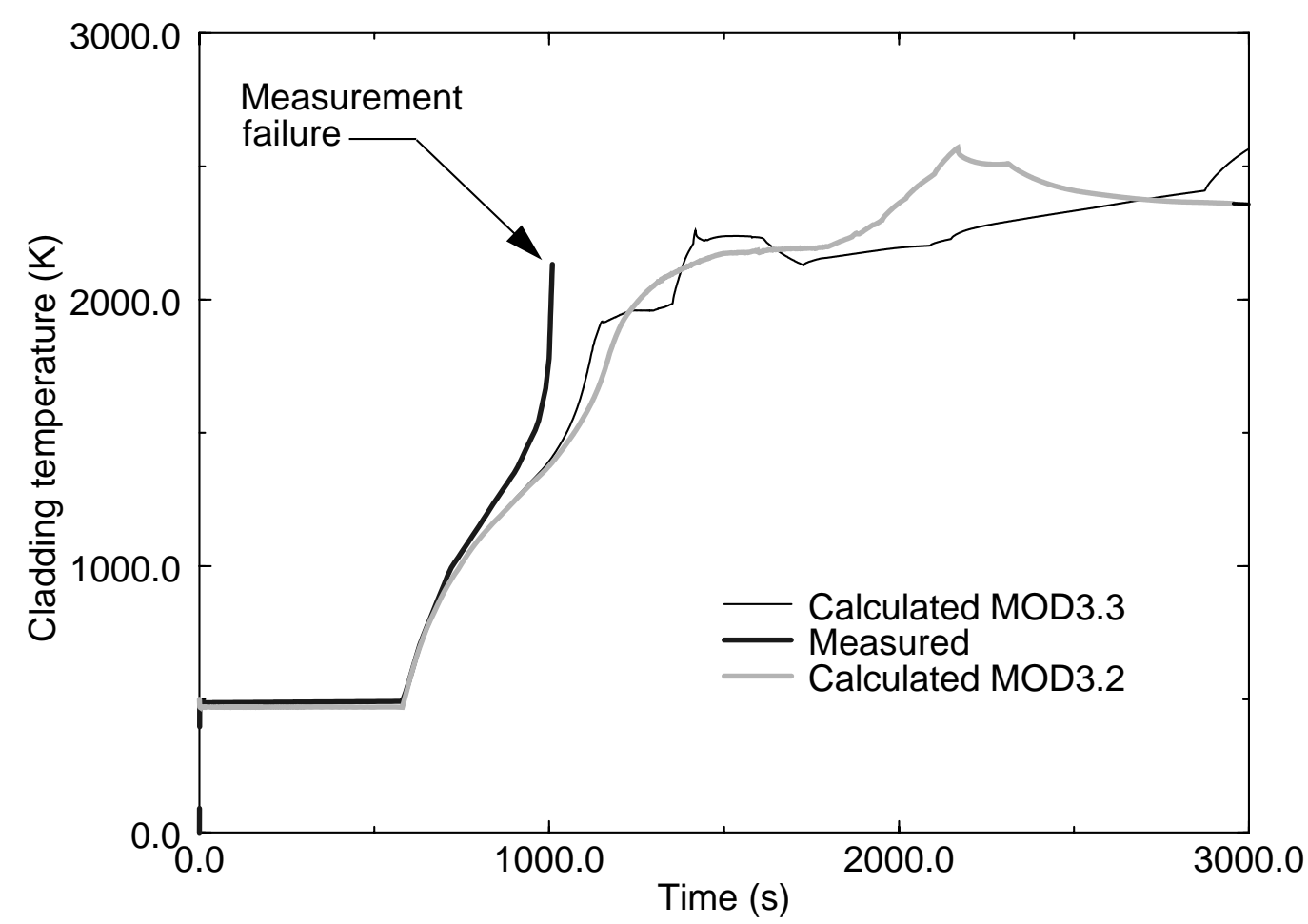

Figure 17. Comparison of calculated and measured cladding temperature for NRU FLHT-5 test at $2.2 \mathrm{~m}$.

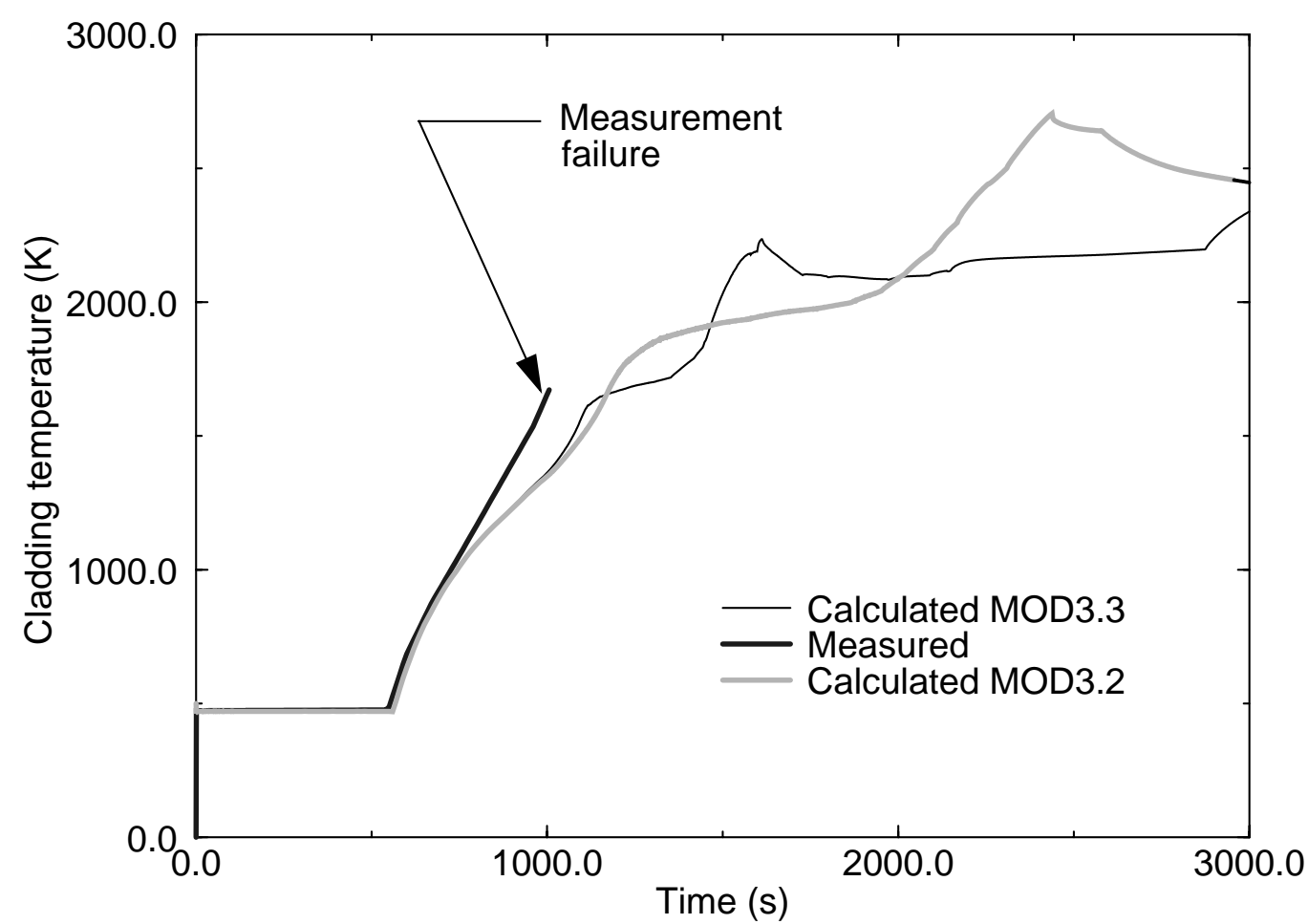

Figure 18. Comparison of calculated and measured cladding temperature for NRU FLHT-5 test at $2.6 \mathrm{~m}$. 


\section{Conclusions}

The modeling of oxygen and hydrogen uptake by the integral diffusion method has improved the SCDAP/RELAP5 calculation of early-phase damage progression. This method is capable of calculating the dissolution of relatively thin oxide layers into the adjacent metallic layer at locations that are steamstarved. This event results in the uptake of hydrogen with the consequence of further cladding heatup, and also results in the cladding at these locations slumping as soon as it melts. As a result, the integral diffusion method in conjunction with the MOD3.3 models for the configuration and integrity of hot, partially oxidized cladding does not overpredict the extent of oxidation in the upper part of fuel rods or significantly underpredict the extent of oxidation in the bottom part of the fuel rods, which was the major deficiency in MOD3.2 that the MOD3.3 early-phase damage progression models had the goal of resolving. The MOD3.3 calculated rate of heatup due to oxidation is generally in better agreement with test results than that calculated by MOD3.2. Both MOD3.3 and MOD3.2 calculate hydrogen production that is generally in good agreement with test results. MOD3.3 has the additional capability of calculating the embrittlement and potential cracking of cladding due to hydrogen uptake.

\section{References}

1. The SCDAP/RELAP5 Development Team, "SCDAP/RELAP5/MOD3.2 Code Manual, Volume II: Damage Progression Model Theory," NUREG/CR-6150, INEL-96/0422, Revision 1, October 1997.

2. D. R. Olander, "Materials chemistry and transport modeling for severe accident analyses in light-water reactors, I: External cladding oxidation," Nuclear Engineering and Design 148 (1994), pages 253-271.

3. D. R. Olander, "Materials chemistry and transport modeling for severe accident analyses in light-water reactors II: Gap processes and heat release," Nuclear Engineering and Design 148 (1994), pages 273292.

4. M. Moalem and D. R. Olander, "Oxidation of Zircaloy by steam," Journal of Nuclear Materials 182 (1991), pages 170-194.

5. M. Steinbruck et al., "Investigations of $\mathrm{H}_{2}$ absorption of Zircaloy-4 at high temperatures," Third International QUENCH Workshop, Karlsruhe, Germany, December 2 - 4, 1997.

6. H. Chung and G. Thomas, "Zircaloy-Oxidation and Hydrogen-Generation Rates in Degraded-Core Accident Situations," CONF-821026-13, International Workshop on the Impact of Hydrogen on Water Reactor Safety, Albuquerque, NM, Oct. 3, 1982.

7. P. Hofmann et al., "Experiments on the Quench Behavior of LWR Fuel Rod Segments," Third International QUENCH Workshop, Karlsruhe, Germany, December 2 - 4, 1997.

8. T. Furuta, H. Uetsuka, and S. Kawasaki, "Estimation of Conservatism of Present Embrittlement Criteria for Zircaloy Fuel Cladding Under LOCA," Zirconium in the Nuclear Industry, Sixth International Symposium, ASTM STP 824, D. G. Franklin and R. B. Adamson, Eds., American Society for Testing and Materials, 1984, pages 734-746.

9. Appendix K, “ECCS Evaluation Models,” 10 CFR Part 50.46.

10. H. M. Chung and T. F. Kassner, "Embrittlement Criteria for Zircaloy Fuel Cladding Applicable to Accident Situations in Light-Water Reactors: Summary Report," NUREG/CR-1344, ANL-79-48, January 1980. 
11. S. L. Seiffert, "Effect of Hydrogen on the Oxygen Embrittlement of Beta-Quenched Zircaloy-4 Fuel Cladding," Zirconium in the Nuclear Industry: Fifth Conference, ASTM STP 754, D. G. Franklin, Ed., American Society for Testing and Materials, 1982, pages 302-328.

12. D. A. Petti et al., "Power Burst Facility (PBF) Severe Fuel Damage Test 1-4 Test Results Report," NUREG/CR-5163, EGG-2542, April, 1989.

13. S. Hagen et al., "CORA Experiments in the Materials Behavior of LWR Fuel Rod Bundles at High Temperatures," Proceedings of the 19th Water Reactor Safety Meeting, NUREG/CP-0119, April 1992.

14. Alan D. Knipe et al., "PBF Severe Fuel Damage Scoping Test, Test Results Report," NUREG/CR4683, EGG-2413, August 1986.

15. The SCDAP/RELAP5 Development Team, "SCDAP/RELAP5/MOD3.2 Code Manual Volume V: Developmental Assessment” NUREG/CR-6150, INEL-96/0422, Revision 1, October 1997.

16. R. Viskanta, R. R. Hobbins and H. Esmaili, "Peer Review of the Modeling of Hydrogen Uptake in Fuel Rod Cladding During Severe Accidents, "ERI/NRC 98-204, USNRC Contract No. 04-92-045, October, 1998.

17. I. Catton, J. O. Cermak, Y. S. Kuo, and A. R. Wazzan, "An Evaluation of Several Aspects of the Hypothetical Loss-of-Coolant Accident for Light Water Reactors," University of California at Los Angelos, Rep. UCLA-ENG-7450, 1974.

18. T. Furuta, H. Uetsuka, and S. Kawaski, "Estimation of Conservatism of Present Embrittlement Criteria for Zircaloy Fuel Cladding Under LOCA," Zirconium for the Nuclear Industry, Sixth International Symposium, ASTM STP 824, 1984, page 734.

19. L. J. Siefken, "Models for the Configuration and Integrity of Partially Oxidized Fuel Rod Cladding at High Temperatures," INEEL/EXT-98-00661Rev1, January 1999.

20. Z. R. Martinson, D.A. Petti, and B. A. Cook, "Vol. 1: PBF Severe Fuel Damage Test 1-1 Test Results Report,” NUREG/CR-4684, EGG-2463, Volume 1, October 1986.

21. D. D. Lanning et al., "Data Report: Full-Length High-Temperature Experiment 5", PNL-6540, April 1988. 


\section{Appendix A}

\section{Oxygen Transport Material Properties}

\section{A1. Diffusion of oxygen in oxidic layer}

A correlation for the coefficient of diffusion of oxygen in the oxide layer ${ }^{\mathrm{A} 1-1}$ for oxide layer temperatures less than $1773 \mathrm{~K}$ is

$\mathrm{D}_{\mathrm{ox}}=75.0 \times 10^{-4} \exp (-22600 / \mathrm{T})$

where

$$
\begin{array}{lll}
\mathrm{D}_{\mathrm{ox}} & = & \text { diffusion coefficient of oxygen in oxide layer }\left(\mathrm{m}^{2} / \mathrm{s}\right), \\
\mathrm{T} & = & \text { temperature of oxide layer }(\mathrm{K}) .
\end{array}
$$

Equation (A-1) is based upon constants for modeling of oxidation by parabolic kinetics, which in turn are based upon data obtained from experiments on the oxidation of Zircaloy cladding.

For an oxide layer temperature greater than $1773 \mathrm{~K}$, a correlation for the coefficient of diffusion of oxygen in the oxide layer ${ }^{\mathrm{A} 1-1}$ is

$$
\mathrm{D}_{\mathrm{ox}}=20 \times 10^{-4} \exp (-24000 / \mathrm{T})
$$

\section{A2. Diffusion of oxygen in metallic layer}

A correlation ${ }^{\mathrm{A} 1-1}$ for the coefficient of diffusion of oxygen in the metallic layer of the cladding is:

$\mathrm{D}_{\mathrm{M}}=4.1 \times 10^{-4} \exp (-25700 / \mathrm{T})$.

\section{A3. Alternative correlations for diffusion of oxygen in oxidic and metallic layers}

An alternative set of correlations for oxygen diffusion coefficients is provided in Reference A1-2. According to this reference, for the temperature range of $1273 \mathrm{~K}$ to $1798 \mathrm{~K}$, the correlations for oxygen diffusion coefficients are:

$\mathrm{D}_{\mathrm{ox}}=8.67 \times 10^{-4} \exp (-40495 / \mathrm{RT})$ 
$\mathrm{D}_{\alpha \mathrm{M}}=1.54 \times 10^{-4} \exp (-48020 / \mathrm{RT})$

$\mathrm{D}_{\beta \mathrm{M}}=0.263 \times 10^{-5} \exp (-28200 / \mathrm{RT})$

where

$$
\begin{array}{lll}
\mathrm{D}_{\alpha \mathrm{M}} & =\quad \text { oxygen diffusion coefficient in alpha phase of cladding }\left(\mathrm{m}^{2} / \mathrm{s}\right), \\
\mathrm{D}_{\beta \mathrm{M}} & =\quad \text { oxygen diffusion coefficient in beta phase of cladding }\left(\mathrm{m}^{2} / \mathrm{s}\right), \\
\mathrm{R} & =\quad 1.987 \mathrm{cal} / \mathrm{mole} \cdot \mathrm{K} .
\end{array}
$$

For temperature in the range of $1798 \leq \mathrm{T} \leq 2098 \mathrm{~K}, \mathrm{D}_{\mathrm{ox}}$ is given the correlation

$\mathrm{D}_{\mathrm{ox}}=0.47 \times 10^{-5} \exp (-25803 / \mathrm{RT})$.

\section{A4. Correlation for binary diffusivity in $\mathrm{H}_{2} \mathrm{O}+\mathrm{H}_{2}$ mixture}

A correlation ${ }^{\mathrm{A} 1-1}$ for the binary diffusivity in a $\mathrm{H}_{2} \mathrm{O}+\mathrm{H}_{2}$ mixture is

tot

where

$$
\begin{array}{lll}
\mathrm{D}_{\mathrm{g}} & = & \text { binary diffusivity in a } \mathrm{H}_{2} \mathrm{O}+\mathrm{H}_{2} \text { mixture }\left(\mathrm{m}^{2} / \mathrm{s}\right), \\
\mathrm{T} & = & \text { temperature of bulk gas }(\mathrm{K}), \\
\mathrm{p}_{\text {tot }} & = & \text { bulk pressure }(\mathrm{MPa}) .
\end{array}
$$

\section{A5. Stoichiometry of oxidic surface}

The relation of $\mathrm{C}_{\mathrm{S}}$ to temperature and the partial pressures of steam and hydrogen in the gas adjacent to the cladding is given by the equation A1-1 
$\mathrm{C}_{\mathrm{s}}=2 .-\frac{\exp (-1.77-12800 / \mathrm{T})}{\left(\mathrm{P}_{\mathrm{H}_{2} \mathrm{O}} / \mathrm{P}_{\mathrm{H}_{2}}\right)^{0.3333}}$

where

$\begin{array}{lll}\mathrm{T} & = & \text { temperature at cladding surface }(\mathrm{K}), \\ \mathrm{P}_{\mathrm{H}_{2} \mathrm{O}} & = & \text { partial pressure of steam }(\mathrm{Pa}), \\ \mathrm{P}_{\mathrm{H}_{2}} & = & \text { partial pressure of hydrogen }(\mathrm{Pa})\end{array}$

According to the above relation, extreme steam starvation is required before the value of $\mathrm{C}_{\mathrm{s}}$ is significantly less than 2.0.

\section{A6. References}

A1-1. D. R. Olander, "Materials chemistry and transport modeling for severe accident analyses in lightwater reactors, I: External cladding oxidation," Nuclear Engineering and Design 148,1994, pages 253-271.

A1-2. A. V. Berdyshev, L. V. Matveev, and M. S. Veshchunov, "Development of the Data Base for the Kinetic Model of the Zircaloy 4/Steam Oxidation at High Temperature $\left(1000^{\circ} \mathrm{C} \leq \mathrm{T} \leq 1825^{\circ} \mathrm{C}\right)$." IBRAE-97-05, Russian Academy of Sciences, Nuclear Safety Institute, March 1997. 